University of South Florida

DIGITAL COMMONS

Digital Commons @ University of

@ UNIVERSITY OF SOUTH FLORIDA

South Florida

USF Tampa Graduate Theses and Dissertations

USF Graduate Theses and Dissertations

$1-28-2009$

\title{
Correlates Of Body Depilation In Men
}

Michael Boroughs

University of South Florida

Follow this and additional works at: https://digitalcommons.usf.edu/etd

Part of the American Studies Commons

\section{Scholar Commons Citation}

Boroughs, Michael, "Correlates Of Body Depilation In Men" (2009). USF Tampa Graduate Theses and Dissertations.

https://digitalcommons.usf.edu/etd/1864

This Thesis is brought to you for free and open access by the USF Graduate Theses and Dissertations at Digital Commons @ University of South Florida. It has been accepted for inclusion in USF Tampa Graduate Theses and Dissertations by an authorized administrator of Digital Commons @ University of South Florida. For more information, please contact digitalcommons@usf.edu. 


\title{
Correlates Of Body Depilation In Men
}

\section{by}

\author{
Michael Boroughs
}

A thesis submitted in partial fulfillment of the requirements for the degree of Master of Arts Department of Psychology College of Arts and Sciences University of South Florida

\section{Major Professor: J. Kevin Thompson, Ph.D. Jennifer Bosson, Ph.D. Jaime Goldenberg, Ph.D.}

Date of Approval:

January 28, 2009

Keywords: body image, hair removal, body dissatisfaction, muscularity, attitudes (C) Copyright 2009 , Michael Boroughs 
Table of Contents

List of Tables $\quad$ iii

Abstract $\quad$ V

Chapter One. Introduction $\quad 1$

Social Comparison Theory 3

Body Image Concerns in Men 5

$\begin{array}{ll}\text { Body Depilation in Men } & 7\end{array}$

Health Implications of Body Depilation $\quad 13$

Women's Preferences for Body Hair on Men 15

Women's Evaluation of Men's Bodies $\quad 19$

$\begin{array}{ll}\text { Goals and Predictions for the Current Studies } & 21\end{array}$

$\begin{array}{ll}\text { Hypotheses } & 22\end{array}$

Chapter Two. Study 1- Method 24

Chapter Three. Study 1- Results \& Discussion 30

Chapter Four. Study 2- Method 45

Chapter Five. Study 2- Results \& Discussion 48

Factor Analysis $\quad 49$

Reliability Estimates $\quad 52$ 
Chapter Six. General Discussion

References

66

Appendices 


\section{List of Tables}

Table 1 Correlation of BoDeQ Scaled Items with other Body Image

Measures

Table 2 Level of Body Hair Growth on Adult Males by Body Site

Table 3 Method and Frequency of Body Depilation by Body Site

Table 4 Correlations between Study 1 Measures with Mean and Standard

Deviation, Cronbach's Alpha and Number of Items

Table $5 \quad$ Men's self-reported body hair growth by body site 40

Table 6 Drive for Muscularity Scale Mean and Standard Deviations

Table 7 Ethnic Differences on the Appearance Evaluation Scale

Table 8 Mean differences by Sexual Orientation on the ATBHM scale

Table 9 Factor Pattern Coefficients of the ATBHM scale from a Principal Axis Factor Analysis with Orthogonal Rotation (original)

Table 10 Factor Pattern Coefficients of the ATBHM scale from a Principal Axis Factor Analysis with Orthogonal Rotation (Final)

Table 11 Item to total correlations for the ATBHM full scale 52

Table 12 Item to total correlations for Factor 1 of the ATBHM scale 53

Table 13 Item to total correlations for Factor 2 of the ATBHM scale 53

Table 14 Item to total correlations for Factor 3 of the ATBHM scale 54

Table 15 Item to total correlations for Factor 4 of the ATBHM scale 54 
Table 17 Mean, Standard Deviation, and Percent Agree or Strongly Agree for items on the ATBHM scale 


\title{
Correlates of Body Depilation in Men
}

\section{Michael Boroughs}

\begin{abstract}
Body depilation is a relatively new area of research inquiry. Although women in many industrialized cultures have engaged in body depilation for some time, this behavior has been documented only recently in men. While originally thought to be the practice of just a small percentage of men, recent studies suggest that more men engage in body depilation than had been previously hypothesized (Boroughs \& Thompson, 2002; Boroughs, Cafri, \& Thompson, 2005; Martins, Tiggemann, \& Churchett, 2008; Tiggemann, Martins, \& Churchett, 2008). Nevertheless, this area of research is understudied and the relationship between body depilation and men's overall body image is poorly understood.

Since much of the documented evidence of men's body depilation is either descriptive anecdotes via media accounts (see Gomes, 2001; Smith, 2000; Stuever, 2000; Stein, 1999; Schuler, 2000) or scientific investigations of the behavior that were undertaken to provide descriptive data about body depilation by men (see Boroughs \& Thompson, 2002; Boroughs, et al., 2005; Martins, et al., 2008; Porche, 2007; Tiggemann, et al., 2008), now the time has come to further the understanding of this behavior in men. The purpose of these studies was to increase both the breadth and depth of our
\end{abstract}


understanding of body depilation in men and its correlates with general body image concerns. A central aim of the first study was to test Social Comparison Theory (Festinger, 1954) as a workable theoretical paradigm to explain the genesis and maintenance of body depilation. The second study investigated women's attitudes towards men's body hair and men's body depilation.

Research questions that have provided the foundation for the design of this study include: a) is there a relationship between men's drive for muscularity, frequency of weekly exercise, and influence by others (via social comparison) that is related to their body depilation behaviors, b) do sexual minority men differ from heterosexual men with regard to depilation behaviors, c) what are women's attitudes toward men's body hair and body depilation by men, and d) how might the attitudes of sexual minority women differ from heterosexual women on the topic of men's body hair and body depilation by men? 
Chapter One

Introduction

Body image is thought to be how individuals' cognitively internalize how they look. Though part of our body image is derived from some form of self-reflection, e.g. looking in the mirror, it does not occur in isolation, but rather in concert with the observed images of others. Social Comparison Theory (Festinger, 1954) may be a theoretical paradigm that helps to explain the body image concerns of both women and men. By comparing our appearance to that of others, individuals then create a cognitive baseline with which to internalize their thoughts about how they look. Because the body image concerns of individuals are generally related to comparisons with others, body depilation is also likely associated with a cultural message for women (Basow \& Braman, 1998; Hope, 1982; Tiggemann \& Kenyon, 1998; Toerien \& Wilkinson, 2003, 2004), and men (Boroughs \& Thompson, 2002; Boroughs, Cafri, \& Thompson, 2005), through some psychological mechanism such as social comparison.

Although body depilation by men has been documented in the literature (see Boroughs \& Thompson, 2002; Boroughs, et al., 2005; Martins, et al., 2008; Tiggemann, et al., 2008), currently the genesis and maintenance of this behavior by men is poorly understood. Even if social comparison is a viable theoretic paradigm to explain this phenomenon among men, other factors are likely to contribute to men's experimentation with body hair removal and reduction. Some possibilities include but are not limited to body dissatisfaction, changes in gendered norms and gender roles, a drive for muscularity, satisfaction with appearance, and others. While thought to be a relatively 
benign behavior whereby individuals modify the way their body appears through home "remedies" such as shaving body hair, body depilation may also be related to some physical and psychological health implications. After all, the process of shaving itself involves taking a very sharp blade and sliding it over the entirety of the body. Indeed if body depilation involves social comparison and internalization of a new cultural norm for men, then the possibility of some psychological effects are evident.

No study has ever examined women's attitudes towards men's engagement in body depilation, although previous studies have examined women's evaluations of men's bodies in general (e.g. Lynch \& Zellner, 1999; Pope, Phillips, \& Olivardia, 2000; Olivardia, Pope, Borowiecki, \& Cohane, 2004; Frederick, Fessler, \& Haselton, 2005), their preferences for body hair on men more specifically (e.g. Dixson, Halliwell, East, Wignarajah, \& Anderson, 2003; Dixson, Dixson, Baoguo, \& Anderson, 2007; Dixson, Dixson, Morgan \& Anderson, 2007), and the attitudes of women and men toward women's failure to engage in body depilation (Basow \& Braman, 1999). Though Social Comparison Theory (Festinger, 1954) is offered as a possible explanation for the genesis of body depilation in men, and the maintenance of its associated behaviors, alternative hypothesis exist including general body image disturbance, dissatisfaction with the appearance of hair at a particular body site, some type of psychopathology such as Body Dysmorphic Disorder, gender role conflict, or the drive for muscularity (i.e. the idea that muscles appear larger when they're not obscured by body hair). The current set of studies will examine each of these possibilities to learn more about this understudied phenomenon among men. 


\section{Social Comparison Theory}

Social Comparison Theory (SCT; Festinger, 1954) captures the idea that people tend to compare themselves to others in an effort to assess how they are doing at some task such as academic achievement, occupational success, or achieving an ideal body shape (Fiske, 2004). In the context of body image research, the use of social comparison may serve as a framework to explain why people look to "like" others to gauge how they look. This theoretical paradigm may aid in a better understanding of the motives for the initiation and maintenance of body depilation in men. Social comparison serves two functions, 1) to understand [those directly observable in the immediate environment], and 2) to motivate behavior [through some change mechanism such as removing body hair and/or working-out]. A key piece of the theory is that people compare themselves with 'similar' others. Men who depilate their body hair would then be expected to socially compare to "like" other men. Similar others in the context of body depilation could be operationally defined as: a) other college students that men observe in their classes, b) other students observed around the college campus, or c) similar others such as other men observed at the gym or another exercise venue.

The adaptation of Social Comparison Theory as a paradigm with which to research body depilation has never been attempted, though SCT has been widely cited in the general body image literature as a theoretical paradigm. The results of the application of SCT with more general body image outcomes for men has thus far been mixed (see Halliwell, Dittmar, \& Orsborn, 2007; van den Berg, Paxton, Keery, Wall, Guo, \& Neumark-Sztainer, 2007; Dittmar, 2005; Hospers \& Jansen, 2005; Miller \& Halberstadt, 2005; Franzoi \& Klaiber, 2007; and Heinberg \& Thompson, 1992). For example, in their 
study of adolescent boys, Morrison, Kalin and Morrison (2004) found fairly strong support for SCT in explaining young men's engagement in universalistic social comparison to predict appearance self-esteem, number of diets to gain weight, use of pathogenic weight control practices, and use of steroids to increase muscle mass. Because this study measured "universalistic social comparison", that is young men comparing themselves to celebrities, sports stars, or other media figures, it failed to take into account the hallmark of Festinger's Social Comparison Theory, namely comparison to "like" others. What may greatly influence body depilation is a comparison of the self to "like" others such as friends, classmates, or gym mates. Nevertheless, the regression analyses conducted by Morrison et al. (2004) indicated that universalistic social comparison was a significant predictor on several criterion measures for males and this study suggested that this type of social comparison may have a fairly powerful effect on appearance selfesteem in young men.

This brings about an important consideration for the use of social comparison as a theoretical framework for males, specifically as it is applied to the context of body image research. Some men may believe that the acknowledgment of comparisons of their physical appearance to actors/models, sports figures, or even "like others" contravenes the traditional sex-role cultural expectation that males should be relatively unconcerned about their physical appearance (Gettelman \& Thompson, 1993; Morrison, Kalin, \& Morrison, 2004). Indeed men in American culture may refrain from more open assessments of the attractiveness of other men because of the fear of being labeled as gay. Men may therefore be resistant to admitting to social comparison of bodily appearance with other men explicitly, though the use of SCT as a framework might explain why men 
choose to engage in body depilation regardless of the reasons they cite for engaging in the behavior. In a previous study of body depilation, researchers found that $40 \%$ of men said they were not influenced whatsoever by others or that they began body depilation on their own accord (Boroughs et al., 2005). Therefore, caution must be used when selecting appropriate items or instruments to collect these data from men.

Though the trend of body hair reduction and removal is relatively recent for men, it is quite possible that men are comparing their bodies to those they perceive as better than themselves, e.g. athletes, gym-mates, classmates, celebrities, or similar others as viewed in pornography, and that this upward comparison to "real" others (classmates or gymmates) along with ideal others (professional athletes, actors, porn stars) may serve to not only facilitate the initiation of body depilation, but may also serve to reinforce and maintain the behavior over time (Hobza, Walker, Yakushko, \& Peugh, 2007). Although comparison with other men on the level of body hair may be new, clearly much research has been conducted over the past two decades into understanding the body image concerns of men. Indeed, the burgeoning level of research into men's overall body image provides a foundation for more specific body image concerns for men such as body depilation.

\section{Body Image Concerns in Men}

Body image research has traditionally focused on the concerns of females (Thompson, 1990). However, in recent years, it has become apparent that men also have issues with their appearance (Thompson, 1990; Boroughs \& Thompson, 2002). In fact, research indicates that men's body image concerns may center around different aspects of appearance than the concerns of women, with a focus on muscularity rather than thinness 
(McCreary, Hildebrant, Heinberg, Boroughs \& Thompson, 2007; Thompson, Heinberg, Altabe, \& Tantleff-Dunn, 1999). For instance, Thompson and Tantleff (1992) found that men desired a larger and more muscular chest size than they currently possessed. Pope, Gruber, Choi, Olivardia, and Phillips (1997) suggested that men's obsession with muscularity might approximate pathological levels and these researchers found that some bodybuilders met criteria for a diagnosis of Body Dysmorphic Disorder (BDD). BDD is a somatoform disorder found in the Diagnostic and Statistical Manual of Mental Disorders (American Psychiatric Association, 1994) with the essential feature being an excessive preoccupation with an imagined or slight defect in appearance, which causes significant distress or impairment in functioning. Although typical complaints for a BDD patient include localization on a body site such as a wrinkle on their face or the shape and/or the size of their nose, the criteria also allow for a simultaneous focus on several body parts. In fact, the diagnostic criteria for this disorder were expanded in the text revision of the DSM-IV-TR to more broadly cover general body image disturbances that approximate pathological levels such as Muscle Dysmorphia (American Psychiatric Association, 2000). Therefore, the possibility of "hair growth" which might be considered by prospective BDD patients to be excessive at various body sites, or even the compulsive removal of body hair, is not beyond the scope of this diagnosis. Phillips and Diaz (1997) suggested that cultural norms and values may influence the content of BDD symptomatology such as the particular site or aspect of body concern and therefore, as social norms change related to body hair on men, so too may men's preoccupation with the appearance of hair on their bodies. 
A shift has occurred in cultural norms, and in the scientific literature, over the past ten to 15 years with body image concerns moving beyond women alone, and towards the full inclusion of men. These changes are not indicative of a reduction in the prevalence of body image disturbance(s) in women, but rather the addition of men's bodies to the group of the objectified and commodified in the culture. Rightly so, researchers have moved from a singular focus on dietary restrictions and the more typical eating disorders symptomatology found mostly in women as strategies to conform to an unrealistic thin ideal, to also examine techniques used by men to change their appearance to a muscular ideal including weight training, excessive aerobic exercise, and the use of steroids and supplements (McCreary, Hildebrandt, Heinberg, Boroughs, \& Thompson, 2007; Thompson \& Cafri, 2007).

Scientific investigators have finally developed research measures and clinical assessments that acknowledge the complexities and idiosyncratic nature of men's body image issues. One such issue of importance to men is body depilation. While normative for women in western and industrial cultures, documentation of body depilation in men is a relatively new phenomenon in contemporary societies.

\section{Body Depilation in Men}

Body depilation can be operationally defined as the reduction or removal of body hair from the neck down. For example, body hair reduction may constitute the use of an electric clipper to shave hair leaving some visible stubble, while body hair removal could involve the use of a razor, laser, or another method to either temporarily or permanently remove visible hair. Both of the described techniques used to remove or reduce the appearance of body hair would be characterized as body depilation. Although 
documentation of the behavior of body depilation in men is new in contemporary societies, the practice of body depilation by men is not. During ancient times, both Egyptian and Greek cultures placed a premium on the appearance of a hairless male body and ancient Egyptian men often shaved their body hair with pumice stones and razors (Luciano, 2001). Much of the art that has survived the times supports this notion with Greco-Roman statuary illustrative of hairless men even in the post-pubescent ephebotypical archetypes. While a hairless norm has endured for women in many western cultures, it fell out of favor for men. The resultant cultural sanction was for only females to engage in body depilation and therefore, until recently, it has been strongly normative within contemporary Western culture for only women to depilate their body hair (Basow \& Braman, 1998; Hope, 1982; Tiggemann \& Kenyon, 1998; Toerien \& Wilkinson, 2003, 2004).

Men, conversely, have not been noted for engaging in body depilation outside of antiquity, perhaps because the presence of body hair has been indelibly associated with masculinity (Basow, 1991; Lewis, 1987; Basow \& Braman, 1998; Tiggemann \& Kenyon, 1998). With relatively few exceptions, such as athletes and bodybuilders, men have not engaged in body depilation because the presence of body hair has traditionally been symbolic of masculinity and therefore associated with men's attractiveness and virility (Basow, 1991; Basow \& Braman, 1998; Lewis, 1987; Tiggemann \& Kenyon, 1998). It appears, however, that the hairless male body ideal has come back into vogue (Luciano, 2001).

According to popular press accounts, shifting cultural ideals have influenced many men to depilate their body hair (Gomes, 2001; Schuler, 2000; Smith, 2000; Stein, 
1999; Stuever, 2000). In fact, several recent empirical accounts suggest that a wide variety of men are concerned with their body hair and are engaging in body depilation behaviors (Boroughs \& Thompson, 2002; Boroughs, et al., 2005; Martins, et al., 2008; Tiggemann, et al., 2008).

In one of the few studies to explore attitudes about men's body hair, Lewis (1987) found that the presence or absence of body hair generally did not affect men's masculine identity. A more recent study found that body hair was a common appearance concern for men with (51.6\%) of the sample naming body hair as a concern, preceded only by head hair (64.5\%), and penis size (61.3\%), and followed by height (48.4\%) (Tiggemann et al., 2008). Basow and Braman (1998) also examined attitudes toward body hair asking both male and female college students to identify their reactions toward women who did not remove their body hair. Both male and female participants made negative attributions toward women who did not remove their body hair; though unfortunately neither the attitudes toward the presence of male body hair nor body depilation by men were evaluated in this study (Basow \& Braman, 1998).

Naturally, society is central in determining "culturally appropriate" behaviors such as the acceptability of body depilation for one or both sexes. Therefore, although body depilation might be characterized as simply the acceptance of socialized norms for women, it is a rejection of those norms for men. An evaluation of the factors underlying men's body depilation might contribute uniquely to an understanding of male appearance concerns and body dissatisfaction.

The recent surge in interest in men's body image by the general population has been the basis for many new investigations into men's body image concerns by 
researchers. Of particular interest are those examinations into men's behaviors related to the depilation of their body hair. Observations and anecdotal reports from various sources suggested the potential for a new form of body image concern that might warrant further investigation: men's engagement in behaviors with the goal of reducing or removing hair from atypical body sites. Popular press accounts have preceded empirical examinations of this phenomenon (see Gomes, 2001; Smith, 2000; Stuever, 2000; Stein, 1999; Schuler, 2000). Such accounts and anecdotal cases suggest that body depilation may occur not only in athletes (predominantly in bodybuilders and swimmers) and sexual minority men, but also in a broad cross-section of men in American society. Body depilation has even been described as "manscaping" by a popular American cable television show (Collins, Metzler \& Williams, 2003) and as a key part of the modal profile of the "metrosexual" by author and social commentator Mark Simpson (1994, 2002).

The result of these documented media accounts coupled with other factors such as systematic field observations was an initial exploratory investigation was undertaken to examine some qualitative and quantitative facets of this relatively new body image concern for men (Boroughs \& Thompson, 2002). Specifically, the goals of this initial study included seeking information from male participants on (a) their frequency of body depilation, (b) reasons behind engaging in the behavior, (c) methods used to reduce or remove body hair, (d) body sites where depilation occurred, and (e) social and affective correlates of body depilation which were measured to determine whether there might be conceptual similarities to more general body image dissatisfaction and disturbance.

Men reported depilating body hair weekly or bi-weekly, gave reasons for depilation that included "to look better", "make muscles look larger", "to look younger", 
or "to feel cleaner", and reported various methods for removing or reducing the hair on their bodies of which regular straight razors (100\%), and electric clippers (65\%) were reported as being used with the highest frequencies (Boroughs \& Thompson, 2002). The areas of the body that were most frequently depilated included the abdomen (90\%), chest and the groin (85\%), and upper legs (70\%). Participants reported feeling dirty (25\%), less muscular, or less presentable just before engaging in body depilation and reported some level of either moderate or situational anxiety (55\%) if they were unable to depilate for some period of time (Boroughs \& Thompson, 2002). The findings from this study do not preclude the possibility that men engage in body depilation to approximate a hairless ideal of attractiveness.

Given the anecdotal reports that support an emerging hairless ideal for men, the observations of experts in the field (e.g., Luciano, 2001), the media attention to the topic (e.g. Gomes, 2001; Schuler, 2000; Simpson, 1994, 2002; Smith, 2000; Stein, 1999; Stuever, 2000), and qualitative data that indicated that men are depilating their body hair in order to increase their attractiveness (Boroughs \& Thompson, 2002), there was sufficient foundation to hypothesize that appearance and body image concerns are a critical underlying factor influencing body depilation in men. In the absence of social norms to guide the behavior, it is expected that some other mechanism must be present in order to influence men to engage in a behavior that has hitherto been considered not masculine.

Clearly, there was a need to confirm the numerous anecdotal accounts and preliminary data that suggested that body depilation is indeed a new and potentially important component of body image concern for men. Therefore, in their study into the 
prevalence and correlates of body depilation in men, Boroughs, Cafri, and Thompson (2005) had several objectives: (1) to estimate the prevalence of body depilation in a sample of men, (2) to assess the characteristics of body depilation by examining the various body sites where depilation takes place, (3) to determine the reasons for body depilation, (4) to assess the methods used to depilate body hair, and (5) to assess the social and affective variables related to body depilation. With a sample of 118 men from a large southeastern university, the results included an estimated prevalence of body depilation in men at (63.6\%) (Boroughs et. al, 2005). Additionally, these authors reported that the body sites most commonly depilated included the groin (74\%), chest (56\%), abdomen (47\%), back of the neck (37\%), arm pits (33\%), and upper legs (27\%) (Boroughs et al., 2005). The method most frequently used by men to depilate their body hair was indicated by whether the goal was to remove the hair completely or only to partially remove the hair (i.e. trim the hair) to leave the appearance of stubble. Boroughs et al., (2005) reported that a regular straight razor garnered the highest frequency (71\%) for complete depilation of body hair, followed by the use of an electric razor (32\%), or electric clippers (29\%) used for trimming which they characterized as body hair reduction.

Despite the main hypothesis that men engaged in body depilation as a strategy to make them appear more muscular, participants in this study reported that their main reasons for depilation were cleanliness (75\%), and sex appeal (69\%) (Boroughs et al., 2005). There were also potential health implications for men who engaged in body depilation and these health risks could be characterized as both physical and psychological. Men reported various injuries related to body depilation such as razor 
burn $(38.7 \%)$, nicks to the skin $(29.3 \%)$, in-grown hairs $(32 \%)$, and cuts to the skin (26.7\%) (Boroughs et al., 2005).

\section{Health Implications of Body Depilation}

In addition to the self-reported physical injuries that could result from body depilation, this behavior might also be associated with a diagnosis of Body Dysmorphic Disorder for some men. For example, in their study, Boroughs et al. (2005) reported that $16 \%$ of the male participants questioned said that it would disturb them if they were hypothetically unable to depilate their body hair, and an additional $18 \%$ rated their anxiety to be in the moderate to extreme range when asked how they would feel if they could not shave or trim their body hair for a few weeks. These findings indicate that, for at least a subset of men, body depilation is critical in maintaining positive feelings and lowering anxiety about their body image and appearance (Boroughs et al., 2005; McCreary, Hildebrandt, Heinberg, Boroughs, \& Thompson, 2007). In addition to the potential for these physical and mental health issues linked to body depilation in men, there are other physical health issues that are of concern. As noted earlier, men have reported using mostly regular razors as the primary instrument with which to remove their body hair. This might explain the recently documented increases in Staphylococcus Aureus Infections identified in men who depilate their body hair (Begier, et al., 2004), as well as an enhanced risk of contracting or transmitting the herpes simplex or human papilloma viruses (Porche, 2007; Trager, 2006). These studies suggest that shaving body hair leaves the skin more susceptible to these diseases because of skin irritation, nicks and cuts, abrasions, and folliculitis (Porche, 2007; Trager, 2006). They also suggest that men may not be as vigilant about the depilation process as women, and that men should 
be educated on improved depilation techniques to prevent medical complications from body depilation (Porche, 2007).

The most recent study of men's body depilation compared heterosexual men $(\mathrm{N}=228)$ with gay men $(\mathrm{N}=106)$ in Australia and found that (33\%) of heterosexual and (63\%) of gay men engaged in depilation of their body hair specifically on either the back or buttocks at least once in their lives (Martins, Tiggemann, \& Churchett, 2008). An even higher percentage of heterosexual (66\%) and gay (82\%) men engaged in depilation of their pubic area (Martins et al., 2008). An overwhelming majority of men (80\%) used shaving as the main technique for body hair removal, and the reasons stated for engaging in body depilation included improved appearance, and better feeling [about the appearance of the body] (Martins et al., 2008).

Given the mounting evidence for an increase in the number of men who engage in this behavior, and both the psychological and physical health ramifications of it, it is important for researchers to gain a better understanding of the motivation by men to engage in this activity, and determine how it relates to both their pursuit of the muscular ideal and their overall body image concerns or body dissatisfaction. Whereas women have traditionally depilated their body hair because of cultural demands, to evade the stigma of body hair, and to avoid the association body hair has with masculinity (Tiggemann \& Kenyon, 1998; Torien \& Wilkinson, 2003, 2004), men have reported that they engage in body depilation because it makes them look cleaner, more sexually attractive, enhances their sexual experience, provides a sense of youthfulness, improves their appearance, and makes them look more muscular (Boroughs \& Thompson, 2002; Boroughs et al., 2005; Martins, et al., 2008; Tiggmann, et al., 2008). Furthermore, there is 
currently no understanding of why some men choose complete depilation of their body hair versus trimming the hair to leave stubble (McCreary, Hildebrandt, Heinberg, Boroughs, \& Thompson, 2007). The latter, though theoretically an option for both sexes, is rarely if ever observed in women and is seemingly exclusive to men's body depilation. One might suspect the remnants of normative masculinity are at play with those men who choose only to trim their body hair, or perhaps this choice is related to women's preferences for some level of body hair on men. Previous research on Western women's attitudes toward body hair on men has shown that they tend to rate men with some body hair on their trunks as more attractive than men with a complete absence of body hair (Dixson, Halliwell, East, Wignarajah, \& Anderson, 2003).

\section{Women's Preferences for Body Hair on Men}

The extant evidence is contradictory on the topic of women's preferences for hair on men's bodies as demonstrated through several cross-cultural works. For example, in her exposé on "Male beauty work in Japan", Laura Miller (2003) reported that the cultural paradigm for men in that country is to have smooth, civilized bodies, and that the removal of their body hair is not only culturally acceptable, but mandated by women. For many centuries, the Japanese have held hairy bodies in some disfavor (Dikötter, 1998; Miller, 2003). In earlier times, hairiness was exemplary of the uncivilized barbarian, as illustrated by the pejorative label in the Japanese language for a white person, "keto", literally "hairy Chinese". In both China (Dikötter, 1998) and Japan, excessive body hair on men came to symbolically represent ethnic or racial boundaries between the in-group and the out-group. For the Japanese, the hirsute male body might 
represent an outsider, foreigner, or else the domestic 'other', such as the Ainu or Okinawans (Miller, 2003).

Indeed, critics note that attitudes towards body hair on men have undergone dramatic changes since the postwar period in Japan (Across, 1989) and some of these attitudes have been empirically demonstrated in other Asian countries. In their recent study of women's preferences for body hair on men, Dixson, Dixson, Baoguo, and Anderson (2007) found that Chinese women preferred male torsos without body hair. Using frontal mesomorphic silhouette figures (Sheldon, 1954), this study presented five frontal male figures varying only in the amount of trunk (chest and abdominal) hair, and found that Chinese women rated the male figure lacking any trunk hair as the most attractive, and that there was a progressive decline in the attractiveness ratings as the level of hair increased among the silhouette figures of men while controlling for all other body shape variables (Dixson et al., 2007). These findings observed with a Chinese sample are contrasted by research into the same topic conducted with a sample of women in the United Kingdom.

British women rated both endomorphic and mesomorphic male body silhouette figures as more attractive when they contained visible body hair on the chest and abdomen (Dixson, Halliwell, East, Wignarajah, \& Anderson, 2003), and in another more recent study conducted with women in central Africa, Bakossi women showed only a small preference for one of the five front-posed mesomorphic figures incorporating varying degrees of trunk (chest and abdominal) hair further obfuscating the conceptualization of women's preferences for body hair on men. The summative results of these studies suggest that culture and socialization may play a great role in influencing 
women's preferences on this issue. The figure lacking body hair was rated least attractive by Bakossi women on average, but only marginally so, and the figure rated most attractive was the second from the most hirsute leaving the only observed statistically significant finding being the average difference between the hairless figure and second from the most hirsute male silhouette (Dixson, Dixson, Morgan \& Anderson, 2007). Apparently somewhat frustrated by the inconsistent findings cross-culturally, the authors of these studies stated that at present, "we do not know how typical the occurrence of masculine chest and abdominal hair is as a secondary sexual characteristic in the Bakossi population (or other populations, e.g. Chinese), although our impression is that many men lack trunk hair suggesting that studies are indicated to measure differential body hair growth on men cross-ethnically" (Dixson et al., 2007, pp. 373).

These studies demonstrate differential ratings of attractiveness of men's bodies as the amount of body hair varies. Although limitations exist in these studies of women's ratings such as the young age and non-married status of the sample in the Chinese study, overall, the results demonstrate differences that might be culturally relevant, biologically determined (actual men in these various ethnicities may tend to be more or less hirsute), or some interaction of both biology and culture. Because so little is known about men's body depilation behaviors, and even less is known about women's preferences for body hair on men, or body depilation by men, part of the goal of the current study will be to examine this important research question.

Though few researchers have examined the idealization of body hair on the male body by others (inclusive of heterosexual women, or sexual minority men), data have been inconclusive on whether body hair on men is considered unattractive (Dixson, et al., 
2007), preferable (Dixson, et al., 2003), or not related to men's masculine selves (Lewis, 1987). The results of the previous studies into this area, however, may have been due to a number of methodological limitations beyond sample characteristics such as age and marital status. For instance, Dixson et al. (2003) found that women rated male silhouette figures as more attractive if they had hair on the chest and abdomen. One shortcoming of this study is that it only investigated women's attitudes toward the presence of body hair on men and did not examine men's attitudes toward hair on their own bodies (Dixson et al., 2003). Conversely the study by Lewis (1987) examined men's feelings about the natural presence or absence of body hair and its relationship to their masculinity, but did not measure this in others, nor was body depilation a consideration in that investigation. Another shortcoming of the Dixson et al. (2003, 2007, 2007) studies is that the body site locations where hair may grow were not examined as variables so that excessive body hair and/or hair on certain parts of the body where it may not be considered appealing were not measured. These studies have been conducted with British, African-Bakossi, Chinese, and Japanese cultures and it remains unclear if there are cultural influences, biological differences, or a combination of both that affect the outcomes reported in these studies. Finally, the studies have lacked psychological components known to play a role in these preferences such as internalization, social norms, and social comparison.

These inconclusive findings suggest a need for a better understanding in this area of body image research, with women as informants on their attitudes toward hair on men's bodies, and also for the collection of data from sexual minorities to examine what differences there may be when gay and bisexual men are included as informants on other men's body hair, and body depilation behaviors. Despite divergent socio-historical and 
cultural traditions, men's body hair issues are firmly rooted in the cultural landscape in both the East (Across, 1989; Dikötter, 1998; Miller, 2003) and West (Lewis, 1987;

Luciano, 2001), and women's preferences, though perhaps muted in the patriarchal past, are beginning to come to light as researchers have begun to give them a voice (Dixson, et al., 2003; Dixson et al., 2007; Dixson et al, 2007). Although women's attitudes toward body depilation by men have never been studied, extant evidence suggests the existence of many incongruities between women's preferences for men's bodies, and what men believe those preferences to be.

\section{Women's Evaluation of Men's Bodies}

In the general body image literature, men have been found to overestimate the degree of muscularity that is found attractive by women (Frederick, Fessler, \& Haselton, 2005), and women estimate that other women idealize more muscular males than they really do (Lynch \& Zellner, 1999). In another study that supported the findings that incongruence exists between the beliefs men have about their body shape, and what women find ideal, Pope, Phillips, and Olivardia (2000) found cross-cultural support for men's belief that women in the U.S., Austria, and France preferred men to ideally have 27 to 32 pounds of additional muscle mass. In that study, researchers were so stunned by this finding that they later asked women at the Austrian data collection site to complete some of the measures given to men (those used with male participants to estimate their actual body shape) to help to conceptualize a supposed female ideal body shape for men and found that the women did not choose the highly muscular body image that men thought they would like, but instead preferred a man who looked very much like an actual average man in their country (Pope et al., 2000). 
These findings were replicated empirically as part of a less ad-hoc design by a more recent examination of 77 American women by Olivardia, Pope, Borowiecki, and Cohane (2004). Here the design was to measure men's ideal and actual body shape via both muscle mass and body fat, and it was found that male participants thought that women wanted them to be significantly more muscular and leaner than the ideal male body shape selected by the female participants (Olivardia et al., 2004). Men's actual (as calculated through skin-fold measurements) and perceived (assessed through the Somatomorphic Matrix on a computer) muscularity was significantly lower than the muscularity of the ideal male body shape chosen by the female participants; men chose an ideal image that was significantly more muscular, and significantly fatter than their perceived female ideal of the male body (Olivardia et al., 2004). These and other findings demonstrate the idea that when it comes to body image, and the expectations that others have, people sometimes make errors in judgment.

So if men erroneously engage in body depilation (or even the drive for muscularity for that matter) beyond what is desired of them by women or other men, what explains this behavior? Anecdotal reports suggest that men's drive for muscularity and perhaps even body depilation is propagated by goals of looking more attractive in an effort to gain the interest of others. Yet, none of these anecdotal reports have suggested that men have received these messages via explicit feedback from others, but rather that they learn, or come to believe this muscular and hairless ideal is what is preferred by the sexual other. One theoretical paradigm would suggest that instead of men learning directly and explicitly about a hairless and muscular ideal, which has hitherto not been supported in the literature (Pope et al., 2000; Olivardia et al., 2004; Frederick, Fessler, \& 
Haselton, 2005) from potential sexual others, they instead learn about it from each other by observation and comparison, this SCT may be implicated in body depilation.

\section{Goals and Predictions of the Current Studies}

The current studies are intended to address these limitations note from the previous research on the relationship between men's body depilation and other body image concerns as well as to investigate women's attitudes toward body depilation by men. Specifically, the studies aim to determine: a) if social comparison is a viable theoretical paradigm with which to explain men's body depilation, b) the level of association between body depilation and other body image related correlates such as exercise habits, appearance evaluation, body areas satisfaction, drive for muscularity, gender role conflict, and body dysmorphia, and c) women's attitudes towards men's body hair and towards men's body depilation through a new scale designed for this study.

Some research questions of interest include: a) do men who engage in body depilation socially compare themselves to other men via explicitly stating that they notice that other men have depilated their body hair in social contexts such as gyms, school, work, or other social situations (amongst strangers); b) is men's body depilation related to age, that is are younger men more likely to engage in the behavior than older men; c) is men's body depilation correlated with hair growth by body site such that the more body sites where men reported hair, the more likely they will depilate; d) what role does men who are more conflicted about their masculinity have with body depilation behaviors; e) do women who go to gyms at a greater frequency have more positive attitudes toward body depilation and hairlessness in men? 
The following hypotheses are offered:

\section{Social Comparison}

1) Body Depilation will be positively associated with gym attendance because this environment provides for ample social comparison of a group of men thought to have a higher prevalence of body depilation, or at the very least, the ability to see and compare themselves to like other on many body sites due to the cultural norms for gym attire.

2) Men who engage in body depilation will be more likely to socially compare themselves to like others in the context of appearance.

\section{Body Image}

3) Body Depilation will be associated with self-reported sexual orientation such that sexual minority men will be more likely than heterosexual men to depilate (empirically driven hypothesis see Boroughs et al., 2005; Martins et al., 2008;

Tiggemann et al., 2008).

4) Men that have a higher drive for muscularity will be more likely to depilate (empirically derived hypothesis given the proposed genesis of modern body depilation in men having its foundation in the body building community).

5) Men who engage in body depilation will have a higher incidence of Body Dysmorphic Disorder (empirically derived hypothesis - the literature suggests that body dissatisfaction can lead to Muscle Dysmorphia, cosmetic surgery, and therefore body depilation may be a strategy used to cope with dysmorphia). 
6) Men who engage in body depilation will have greater body dissatisfaction and less satisfaction with their appearance. (empirically driven hypothesis because findings suggest that contemporary American men display substantial body dissatisfaction (Olivardia et al., 2004) and one explanation for body depilation may be dissatisfaction with body hair growth). 


\section{Chapter Two}

\section{STUDY 1}

Method

\section{Participants}

Study 1 included a sample of 360 male participants from a large southeastern American university. The age ranged from 18 to $44(\mathrm{M}=20.92, \mathrm{SD}=3.99)$ with a modal age of 18 years, which accounted for $24.1 \%$ of the total sample. The majority of the sample was single (94.2\%), grew-up in the United States (92.2\%), and identified as heterosexual (91.4\%). Euro-American was the largest reported ethnicity (61.1\%), followed by Latinos (14.5\%), African Americans (12.2\%), Asian Americans (10.5\%), and Native Americans $1.7 \%$. The sample was relatively evenly distributed across year in college with $1 \%$ post-baccalaureate students, $19.3 \%$ seniors, $24.1 \%$ juniors, $19.8 \%$ sophomores, and $21.4 \%$ freshman.

A majority of the sample $(74.3 \%)$ reported viewing pornography for some period of time over the span of a week with the average being 56 minutes, and the median 30 minutes. There were significant differences found between heterosexual ( $M=51.7$ minutes, $\mathrm{SD}=133.5)$ and sexual minority $(\mathrm{M}=98.9$ minutes, $\mathrm{SD}=92.4)$ men in pornography viewership, $F(1,357)=3.69, p=.05$.

A total of 45 sexual minority men $(8.6 \%)$ participated in the study. Sexual minorities compose a group whose sexual identity, orientation, attractions, or behaviors differ from the majority of the surrounding culture or society (Ullerstam, 1966). For this study, the term sexual minorities is operationalized as gay or bisexual men, but also 
lesbians or bisexual women as is noted in study 2. The "screen-in" question which selected men for the sexual minority protocol rather than the heterosexual protocol was a single question on a Mass Testing Screener Survey used to manage the USF psychology department's research participant pool. The question read, "How would you describe your sexual attraction towards others?" All participants answered this question with a 5point Likert response set from 1=Attracted only to the same sex (gay) to $5=$ Attracted to only the opposite sex (straight). Participants answering " 5 " on this question were directed to the heterosexual protocol, whereas all other participants whose answers ranged from 1 to 4 on this item were directed to the sexual minority protocol. The sexual minority protocol included one additional measure outlined in Study 2.

Four human sexuality questions were asked of all Study 1 participants eliciting ratings on a 5-point Likert scale having to do with Sexual Attraction, Sexual Behavior, Sexual Fantasy, and Sexual Orientation (Identity). The responses for the sexual minority men were incongruent, i.e. some men identified as "heterosexual" despite admitted sexual attraction for, behavior with, or fantasy about other same sex individuals. In order to determine whether these cases should remain within the sexual minority group for the purpose of data analyses, or be moved to the heterosexual group, a criterion was established whereby any case that fell within the sexual minority protocol that responded to all four sexuality questions as "totally heterosexual" would be moved into the heterosexual group. No such cases existed; therefore all 45 sexual minority cases remained labeled as being within the sexual minority group, with one case deleted because all items on every questionnaire were unanswered. 
For the sexual minority male sub-sample, the mean age was $\mathrm{M}=21.55, \mathrm{SD}=5.56$, and the modal age was 18 years, with $27.3 \%$ of the sub-sample reporting this age. The majority (95.5\%) were socialized in the United States, and 56.8\% were Euro-American, 22.7\% Latino, 11.4\% African-American, 6.8\% Asian-American, and 2.3\% NativeAmerican.

Chi-square tests were performed to measure the homogeneity of diversity between the heterosexual and sexual minority groups and no significant differences were observed.

Measures

Social Comparison:

Physical Appearance Comparison Scale (PACS; Thompson, Heinberg, \& Tantleff, 1991)

The five-item PACS was used to measure the tendency of men to make personal physical appearance-related comparisons with like others in various social situations. Participants indicated on a scale from 1 to $5(1=$ never, $5=$ always $)$ the frequency with which they carried out specific physical comparisons with others (e.g., "In social situations, I sometimes compare my body shape to the body shape of other people"). Items 2 ("The best way for a person to know if they are overweight or underweight is to compare their figure to the figure of others") and 5 ("In social situations, I sometimes compare my figure to the figure of other people") were modified for use with the male sample in Study 1. The word "figure" was replaced with the phrase "body shape" each time it appeared in these two items to adjust to a more comfortable linguistic syntax for men. The authors report an alpha of .61, though the observed alpha for this sample was .68. In the current study, one of the items, which is the only reverse-coded item on the 
scale (item 4), had a negative correlation with the item total. Therefore, this item was deleted and the resulting observed alpha for the PACS was $\alpha=.78$.

\section{Body Image:}

Body Depilation Questionnaire (BoDeQ; Boroughs, Cafri, \& Thompson, 2005)

This 16-item measure was used to measure descriptive information about the body depilation habits of men including aspects of mood and anxiety associated with hypothetical limitations being put on men's ability to depilate. There are three item clusters with good internal consistencies (Cronbach's Alphas): Importance of depilation before being seen by others, $\alpha=.77$ (item 9 a, b, c); feelings about inability to depilate, $\alpha=$ .77 (item $13 \mathrm{a}, \mathrm{b}$ ); and observation of depilation by other men, $\alpha=.94$ (item $16 \mathrm{a}, \mathrm{b}, \mathrm{c}, \mathrm{d}$ ). Because most items on the BoDeQ are check-list style, the above alphas are reported only for the continuously scaled items on this measure.

As an adjunct to the PACS in measuring social comparison, four additional items were added to the end of the BoDeQ instrument to directly measure men's social comparison and observation of other men that depilate their body hair in four different contexts: a) at the gym, b) among other male friends, c) among classmates, and d) among other men elsewhere in the general population (see Appendices).

Body Dysmorphic Disorder Examination, Self-Report (BDDE-SR; Rosen \& Reiter, 1996)

This 32-item self-administered questionnaire was used to measure the cognitive and behavioral symptoms of Body Dysmorphic Disorder. The BDDE-SR has acceptable test-retest reliability $(r=.94)$, internal consistency $(r=.95)$, and concurrent validity with other body image questionnaires ( $r s=.68$ to .83 ) (Rosen, Reiter, \& Orosan, 1995). The BDDE-SR is considered a psychometrically sound instrument that allows for an accurate 
diagnosis of BDD and assesses for typical BDD symptomatology that can be targeted in treatment. The observed Cronbach's Alpha for this sample was $\alpha=.94$.

Multidimensional Body Self-Relations Questionnaire (Brown, Cash \& Mikula, 1990)

The MBSRQ Appearance Scale (MBSRQ) is a 34-item measure that consists of 5 subscales: 1) Appearance Evaluation (AES), 2) Appearance Orientation, 3) Overweight Preoccupation, 4) Self-Classified Weight, and 5) the Body Areas Satisfaction Scale (BASS). The MBSRQ is widely used in body image research and has adequate psychometric properties with test-retest reliability $(r=.91)$ and internal consistency $(r=$ .88) (Brown, Cash \& Mikula, 1990). Two of the five MBSRQ sub-scales: the AES and the BASS were administered to participants.

Appearance Evaluation Scale (MBSRQ-AES) The AES is a 7- item subscale that rates feelings of physical attractiveness or unattractiveness, and satisfaction with one's looks (Cash et al., 1990). The observed Cronbach's Alpha for this sample was $\alpha=.90$.

Body Areas Satisfaction Scale (MBSRQ-BASS) The BASS is a 9-item subscale that asks participants for satisfaction ratings for specific body sites and parameters. One item was added to this subscale, participants was also asked to rate their satisfaction with their body hair, including the amount, locations, and coarseness. The observed Cronbach's Alpha for this sample was $\alpha=.86$.

Drive for Muscularity Scale (DMS; McCreary \& Sasse, 2000)

This 15-item scale is designed to assess attitudes toward muscularity. Items are rated on a 6 -point Likert scale ranging from $1=$ always to $6=$ never, and then reverse scored so that higher scores indicate a greater drive for muscularity. The authors (McCreary \& Sasse, 2000) report an alpha $=.84$, and for this sample, the observed 
Cronbach's alpha was $\alpha=.89$ indicating slightly greater internal consistency than the originally published sample.

Gender-Role Conflict (Masculinity):

Gender Role Conflict Scale (GRCS; O'Neil, Helms, Gable, David \& Wrightsman, 1986)

This is a 37-item questionnaire designed to measure men's endorsement of traditional male gender roles in the United States and the negative consequences that result from violations of this role. Four factors were measured with this instrument including: 1) Success, Power, and Competition, 2) Restrictive Emotionality, 3)

Restrictive Affectionate Behavior between Men, and 4) Conflict between work and family relations. Participants respond to items using a 6-point scale from 1=strongly disagree to $6=$ strongly agree, with higher scores indicating greater gender role conflict. Test-retest reliability is adequate (ranging from .72 to .86 , O'Neil et al., 1986) and the four factor structure was found to be internally consistent with alphas ranging from .75 to .85 (O'Neil et al., 1986). The observed Cronbach's alpha for this sample was $\alpha=.93$. 


\section{Chapter Three}

\section{Results and Discussion}

The scaled items on the BoDeQ related to feedback from others on body depilation and the importance of depilating before being seen by friends, significant others, or strangers were not associated with the measures of social comparison (i.e. the PACS or the four BoDeQ items related to observations that others have engaged in body depilation). Conversely, the BoDeQ scaled items having to do with anxiety if participants were unable to depilate for a few weeks, and positive or negative feelings when body hair is not depilated, were associated with some of the measures of body image, namely the AES, BASS, BDDE-SR, and the DMS. For example, a negative correlation $(r=-.269)$ was observed between the BoDeQ feeling items (feeling good) and body dysmorphia measured through the BDDE-SR . Negative correlations were also observed between appearance evaluation $(r=-.442)$ and body areas satisfaction $(r=-.413)$ and body dysmorphia indicating that men who have great appearance satisfaction and greater body areas satisfaction were less likely to have experience body dysmorphia. The results of these Pearson correlations appear in the Table 1.Table 1. Correlation of BoDeQ scaled items with other Body Image Measures

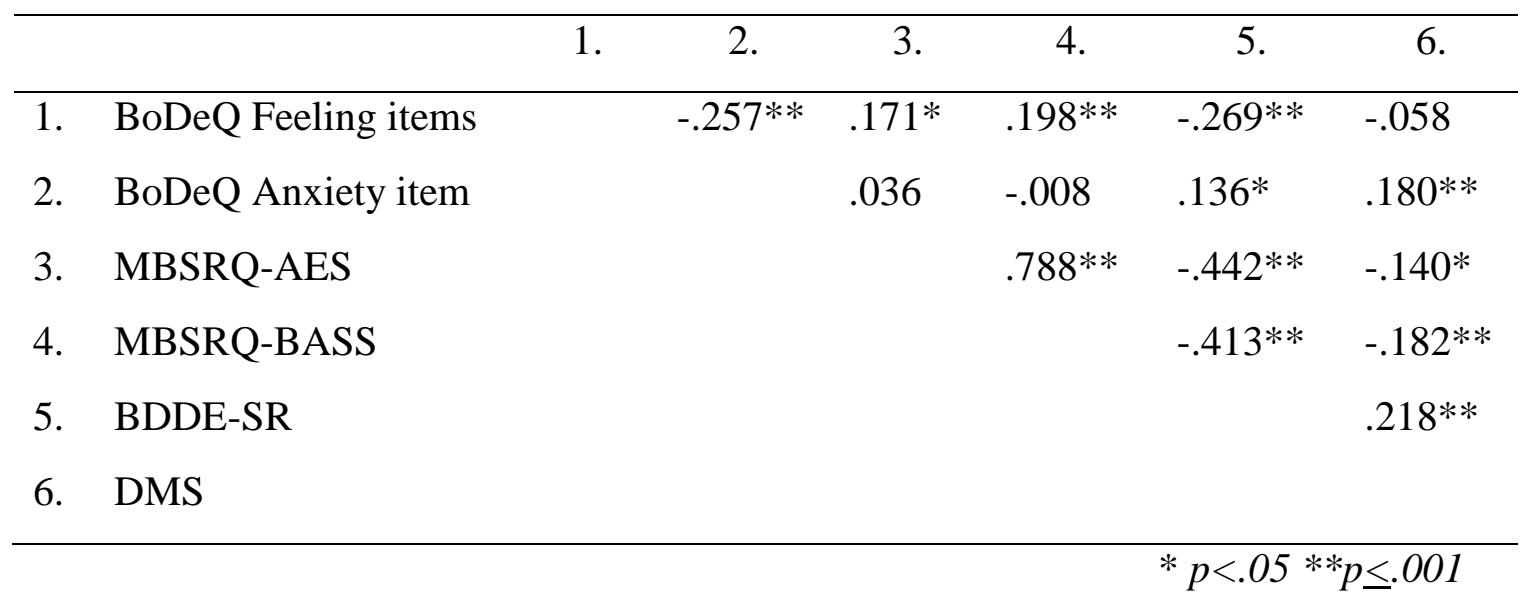


In terms of men's self-reported body hair growth by site, the following was reported by participants that were asked to use a 1 to 5 scale, with $1=$ no hair (or very little hair) and 5= very hairy, to indicate the amount of hair that grows on the following body sites listed in table 2 . The results indicate that the body sites with the greatest amount of hair reported were the groin $(\mathrm{M}=3.4, \mathrm{SD}=1.0)$, legs $(\mathrm{M}=3.3, \mathrm{SD}=.99)$, and armpits $(\mathrm{M}=3.2, \mathrm{SD}=.95)$. Approximately $2 / 3$ of men reported little to no hair on their backs while 1/3 of men reported having a hairless chest. See Table 2 for the results. Table 2. Level of Body Hair growth on Adult Males by Body Site

\begin{tabular}{llllllll}
\hline & $\mathrm{N}$ & $\begin{array}{c}\text { (1) No } \\
\text { hair/very } \\
\text { little hair }\end{array}$ & \multicolumn{1}{c}{$(2)$} & \multicolumn{1}{c}{$(3)$} & \multicolumn{1}{c}{$(4)$} & $\begin{array}{l}\text { (5) Very } \\
\text { hairy }\end{array}$ & M(SD) \\
\hline 1-Neck & 358 & $56.7(203)$ & $27.7(99)$ & $9.5(34)$ & $2.8(10)$ & $3.4(12)$ & $1.7(.99)$ \\
2-Shoulders & 359 & $74.1(266)$ & $18.1(65)$ & $5.3(19)$ & $1.4(5)$ & $1.1(4)$ & $1.4(.75)$ \\
3-Armpits & 355 & $4.5(16)$ & $15.8(56)$ & $45.6(162)$ & $25.9(92)$ & $8.2(29)$ & $3.2(.95)$ \\
4-Chest & 358 & $33(118)$ & $26.5(95)$ & $20.9(75)$ & $12.3(44)$ & $7.3(26)$ & $2.3(1.3)$ \\
5-Abdomen & 357 & $24.6(88)$ & $34.7(124)$ & $21.8(78)$ & $12.6(45)$ & $6.2(22)$ & $2.4(1.2)$ \\
6-Groin & 358 & $4.5(16)$ & $12.6(45)$ & $38.8(139)$ & $29.9(107)$ & $14.2(51)$ & $3.4(1.0)$ \\
7-Back & 359 & $61.8(222)$ & $22.8(82)$ & $10.9(39)$ & $1.9(7)$ & $2.5(9)$ & $1.6(.94)$ \\
8-Buttocks & 358 & $28.2(101)$ & $32.7(117)$ & $23.7(85)$ & $9.5(34)$ & $5.9(21)$ & $2.3(1.2)$ \\
9-Arms & 358 & $16.5(59)$ & $39.7(142)$ & $29.1(104)$ & $10.9(39)$ & $3.9(14)$ & $2.5(1.0)$ \\
10-Hands & 358 & $47.5(170)$ & $30.7(110)$ & $15.4(55)$ & $4.7(17)$ & $1.7(6)$ & $1.8(.97)$ \\
11-Legs & 358 & $3.4(12)$ & $16.2(58)$ & $38.3(137)$ & $30.4(109)$ & $11.7(42)$ & $3.3(.99)$ \\
12-Feet & 357 & $37.5(134)$ & $35.9(128)$ & $16.8(60)$ & $7.3(26)$ & $2.5(9)$ & $2.0(1.0)$ \\
\hline
\end{tabular}

Of those men who engaged in body depilation at any body site, the primary sites reported by men for depilation behaviors were the groin (92.7\%), abdomen (61\%), back of the neck (57.6\%) and chest (56.9\%). The most frequently reported methods used for reducing or removing body hair were body site dependent, though a regular razor and 
either an electric razor or electric clippers were the most common methods. Other than these three body depilation methods, the only other methods reported by $1 \%$ or more of the sample were scissors and depilatory creams. For example, participants reported using scissors for the groin/pubic area (13.6\%), armpits (9.5\%), or abdomen (2.5\%) and depilatory creams for the chest (1.3\%), buttocks (1.4\%), and abdomen (1.2\%). Table 3 contains the methods used for body depilation by body site along with the average frequency of body hair reduction or removal.

Male participants reported that they had been depilating their body hair from less than one year to 20 years with $29 \%$ of the sample reporting body depilation behaviors for one year or less, $\mathrm{M}=3.7$ (years), $\mathrm{SD}=3.1$ (years). Body image issues were key factors in explaining body hair reduction and removal behaviors. The main reasons noted for depilation included: cleanliness (61.9\%), sex appeal (57.2\%), better sexual experience (29.7\%), and body definition/muscularity (20.8\%). Also of interest are the various injuries that were reported as a result of removing or reducing body hair, including razor burn (35.6\%), nicks to the skin (31.9\%), in-grown hairs (28.9\%), and cuts to the skin (24.7\%). Twenty-five percent of the sample reported no occurrence of injuries.

Although this study more directly tested Social Comparison Theory as a theoretical paradigm for the initiation and maintenance of body depilation in men, participants were asked as part of the BoDeQ assessment about factors that influenced their first depilation experiences and variables related to hair reduction and removal behaviors were also examined. Participants reported that the influences for the genesis of body depilation included: no influence by others or tried depilation on their own accord (39.2\%), overheard someone talking about it (22.8\%), talked to someone about it 
(21.4\%), influenced by media (18.9\%), saw that others engaged in the practice (13.9\%), and observed a known person doing it (11.4\%).

Table 3. Method and Frequencies of Body Depilation by Body Site

\begin{tabular}{|c|c|c|c|c|}
\hline Body Site & Method & $\%$ & Frequency- M & $(\mathrm{SD})$ \\
\hline \multirow{3}{*}{ 1-Neck } & Regular Razor & 34.2 & \multirow{3}{*}{4.7} & \multirow{3}{*}{$(1.7)$} \\
\hline & Electric Razor & 12.8 & & \\
\hline & Electric Clippers & 10.7 & & \\
\hline \multirow[t]{3}{*}{ 2-Shoulders } & Regular Razor & 14.5 & \multirow{3}{*}{5.6} & \multirow{3}{*}{$(1.8)$} \\
\hline & Electric Razor & 6.3 & & \\
\hline & Electric Clippers & 2.7 & & \\
\hline \multirow[t]{4}{*}{ 3-Armpits } & Regular Razor & 10.8 & \multirow[t]{4}{*}{5.6} & \multirow[t]{4}{*}{ (1.4) } \\
\hline & Electric Razor & 12.6 & & \\
\hline & Electric Clippers & 11.3 & & \\
\hline & Scissors & 9.5 & & \\
\hline \multirow[t]{5}{*}{ 4-Chest } & Regular Razor & 27 & \multirow[t]{5}{*}{5.2} & \multirow{5}{*}{$(1.6)$} \\
\hline & Electric Razor & 13.1 & & \\
\hline & Electric Clippers & 13.1 & & \\
\hline & Depilatory Creams & 1.3 & & \\
\hline & Scissors & 1.3 & & \\
\hline \multirow[t]{5}{*}{ 5-Abdomen } & Regular Razor & 27 & 5.2 & \multirow{5}{*}{$(1.5)$} \\
\hline & Electric Razor & 15.4 & & \\
\hline & Electric Clippers & 14.5 & & \\
\hline & Scissors & 2.5 & & \\
\hline & Depilatory Creams & 1.2 & & \\
\hline \multirow[t]{4}{*}{ 6-Groin/Pubic Area } & Regular Razor & 35.3 & 5.2 & \multirow{4}{*}{$(1.4)$} \\
\hline & Electric Razor & 21.7 & & \\
\hline & Electric Clippers & 20.6 & & \\
\hline & Scissors & 13.6 & & \\
\hline \multirow[t]{3}{*}{ 7-Back } & Regular Razor & 11.8 & 5.8 & \multirow{3}{*}{ (1.6) } \\
\hline & Electric Razor & 3.6 & & \\
\hline & Electric Clippers & 3.2 & & \\
\hline \multirow[t]{4}{*}{ 8-Buttocks } & Regular Razor & 12.7 & 5.7 & \multirow{4}{*}{$(1.6)$} \\
\hline & Electric Razor & 7.7 & & \\
\hline & Electric Clippers & 5.0 & & \\
\hline & Depilatory Creams & 1.4 & & \\
\hline \multirow[t]{3}{*}{ 9-Arms } & Regular Razor & 11.9 & 5.6 & (1.9) \\
\hline & Electric Razor & 4.6 & & \\
\hline & Electric Clippers & 3.2 & & \\
\hline 10-Hands & Regular Razor & 7.5 & 5.7 & (1.9) \\
\hline & Electric Razor & 5.2 & & \\
\hline & Electric Clippers & 1.4 & & \\
\hline 11-Legs & Regular Razor & 5.0 & 5.8 & $(1.8)$ \\
\hline & Electric Razor & 8.3 & & \\
\hline & Electric Clippers & 6.0 & & \\
\hline 12-Feet & Regular Razor & 12.1 & 5.8 & $(1.8)$ \\
\hline & Electric Razor & 5.1 & & \\
\hline & Electric Clippers & 2.8 & & \\
\hline
\end{tabular}


They were also asked if their body depilation behaviors were curtailed for certain reasons such as: (a) relationship status, (b) during the off-season of a sport, or (c) climatic differences (i.e., colder weather). Sixty-seven of the 360 participants (18.6\%) said that shaving or trimming became less important when they were not in a romantic relationship. Forty-seven (13.1\%) said that climatic 'off-season' made the behavior less important. Another 27 participants (7.5\%) reported that the off-season for a sport made body depilation less important to them. One hundred-fifty eight (44\%) reported no changes in depilation behaviors over time, and 37 participants (10.3\%) said that they had not been depilating long enough to respond to the question.

Affective dimensions of body depilation were assessed. Participants were asked to rate the importance of removing or reducing body hair prior to social contact with others. The scale for this series of questions was as follows: 5 (extremely important) to 1 (not important). The observed Cronbach's Alpha for the scale with this sample was $=.77$. Ratings of importance for the removal or reduction of body hair prior to social contact were variable, though steady, across the three reference groups in question. Participants reported depilation prior to social contact as moderately important before having interactions with significant others $(\mathrm{M}=3.11, \mathrm{SD}=1.34)$, but slightly to somewhat important before being seen by the general public $(\mathrm{M}=2.67, \mathrm{SD}=1.39)$, or friends $(\mathrm{M}=$ 2.65, $\mathrm{SD}=1.26$ ). Participants were asked to describe their feelings related to a hypothetical inability to remove or reduce body hair in general, and after a few days without depilation. The scale for these items was as follows: 1 (extremely good) to 5 (extremely bad) with the observed alpha for this scale was $=.77$. The average score for the item related to general inability to depilate was $(\mathrm{M}=2.58, \mathrm{SD}=.84)$, which indicated 
feelings of ambivalence, however, $10 \%$ of the sample rated this item as a "4" or " 5 " indicating "moderately to extremely bad feelings." The average rating was also in the midrange for the item that assessed feelings after going a few days without depilation (M $=2.64, \mathrm{SD}=.80) ; 1 \%$ of the sample rated this item as a " 5, " and $7.8 \%$ rated it as a "4." Participants were also asked to hypothetically estimate their level of anxiety if they could not depilate their body hair for a few weeks. The scale for this item was: 1 (not anxious at all) to 5 (extremely anxious). On an average, participants' anxiety rating was slightly anxious $(\mathrm{M}=1.85, \mathrm{SD}=1.09)$, though $9.9 \%$ of the sample rated their anxiety as moderate to extreme if they could not depilate their body hair for a few weeks.

Although clothing usually covers many of the oft-reported body sites where depilation occurs, several participants reported depilating parts of their bodies that are regularly exposed to the public (e.g., forearms or legs). Almost one-half of the participants (45.3\%) reported that friends or acquaintances had taken notice of their body depilation and had given them direct feedback about it. Average scores indicated that the feedback was moderately positive $(\mathrm{M}=3.4, \mathrm{SD}=.88$; range from 1 to 5 , on a scale of 1 extremely negative to 5-extremely positive). While most (88.4\%) participants reported either neutral or positive feedback about their body depilation, $11.7 \%$ of participants reported moderate to extremely negative comments from others about their body depilation.

Pearson correlations were computed for all of the measures used in Study 1. The scaled items for the BoDeQ, Cronbach's alpha $=.26$ was not unexpected since these items are unrelated. The observed alpha for four adjunct items added to the BoDeQ to test for social comparison among body depilators was $=.94$. Therefore, the added social 
comparison items were partitioned from the other scaled items on the BoDeQ for the purpose of presenting the inter-correlation matrix of all measures used in study. The social comparison items from the BoDeQ had a positive statistically significant correlation with the PACS, another measure of social comparison, $r=.28, p<.001$, as well as with the BDDE-SR, measuring body dysmorphia, $r=.21, p<.001$, the DMS, a measure of drive for muscularity, $r=.28, p<.001$, and the GCRS measuring gender role conflict, $r=.19, p<.001$. These significant correlations, though relatively weak, suggest that men who depilate their body hair and observe that other men do so as well have higher scores on measures of physical appearance social comparison, Body Dysmorphic Disorder, drive for muscularity and gender role conflict. The most notable observed correlations between the measures were the PACS and the BDDE-SR, $r=.40, p<.001$, and the MBSRQ-AES and the BDDE-SR, $r=-.44, p<.001$. These results indicate that body dysmorphia in general and possibly Body Dysmorphic Disorder are positively associated with greater levels of physical appearance social comparison and negatively associated with higher levels of appearance evaluation. Further, the PACS was positively associated with the DMS, $r=.38, p<.001$, and the GCRS, $r=.34, p<.001$ indicating the physical appearance social comparison is related to greater drive for muscularity and greater gender role conflict. In addition, there were several other statistically significant observed correlations, those these were more weakly correlated. For example, greater gender role conflict was negatively associated with body areas satisfaction, $r=-.28, p<.001$, and also negatively associated with appearance evaluation, $r=-.19, p<.001$. Negative correlations found with the body image measures indicate that greater gender role conflict is related to poorer body satisfaction. Full results from these correlations are presented in Table 4. 
Table 4. Correlations between Study 1 Measures with Means, SD, and Cronbach's Alpha

\begin{tabular}{|c|c|c|c|c|c|c|c|c|c|}
\hline & & 1 & 2 & 3 & 4 & 5 & 6 & 7 & 8 \\
\hline 1. & BoDeQ & & .070 & -.007 & -.113 & .019 & -.010 & .081 & .029 \\
\hline 2. & $\begin{array}{l}\text { BoDeQ- } \\
\text { SC }\end{array}$ & & & $.275 * *$ & $.207 * *$ & -.076 & -.052 & $.278 * *$ & $.194 * *$ \\
\hline 3. & PACS & & & & $.401 * *$ & $-.189 * *$ & $-.169 * *$ & $.375 * *$ & $.340 * *$ \\
\hline 4. & BDDE-SR & & & & & $-.442 * *$ & $-.413 * *$ & $.218^{* *}$ & $.226^{* *}$ \\
\hline 5. & $\begin{array}{l}\text { MBSRQ- } \\
\text { AES }\end{array}$ & & & & & & $.788 * *$ & $-.140 *$ & $-.194 * *$ \\
\hline 6. & $\begin{array}{l}\text { MBSRQ- } \\
\text { BASS }\end{array}$ & & & & & & & $-1.82 * *$ & $-.281 * *$ \\
\hline 7. & DMS & & & & & & & & $.386 * *$ \\
\hline 8. & GRCS & & & & & & & & \\
\hline \multicolumn{2}{|c|}{ M } & 20 & 9.5 & 14.4 & 36.5 & 25.2 & 35.6 & 43.3 & 133.9 \\
\hline \multicolumn{2}{|c|}{ SD } & 3.3 & 4.3 & 3.6 & 25.5 & 5.5 & 6.8 & 13.9 & 28.6 \\
\hline \multicolumn{2}{|l|}{$\alpha$} & .26 & .94 & .78 & .94 & .90 & .86 & .89 & .93 \\
\hline \multicolumn{2}{|c|}{ \# of items } & 7 & 4 & 5 & 32 & 7 & 10 & 15 & 37 \\
\hline
\end{tabular}

In order to test the hypothesis that body depilation is related to social comparison that occurs in the context of gym attendance, total exercise was computed by the sum of aerobic and anaerobic exercise both inside and outside of a gym. Heterosexual men reported higher $(\mathrm{M}=244$ minutes per week, $\mathrm{SD}=265)$ total exercise time than gay men $(\mathrm{M}=92$ minutes per week, $\mathrm{SD}=114), t(358)=2.04, p=.04$. This statistically significant group difference was realized only when comparing gay men (inclusive of only those who selected " 1 " on all four items measuring sexuality) with all other men in the sample, and was not observed when comparing all sexual minority men with heterosexual men. T-tests did not however reveal significant differences between body depilators ( $M=136$ minutes per week, $\mathrm{SD}=188)$ and the non-depilation group $(\mathrm{M}=110$ minutes per week, 
$\mathrm{SD}=205), t(351)=.93, p>.05$ on in-gym exercise which was the sum of both aerobic and anaerobic exercise that took place in a gym only.

An independent samples t-test was conducted to determine whether social comparison occurred at a greater rate for the body depilation group when compared with the non-depilation group. Men who engaged in body depilation $(\mathrm{M}=11.7, \mathrm{SD}=3.4)$ had significantly higher scores on the PACS (Thompson, Heinberg, \& Tantleff, 1991) when compared with the non-depilation group $(\mathrm{M}=10.7, \mathrm{SD}=3.0), t(353)=2.15, p=.032$. An adjunct set of four items were included with the BoDeQ-SC (Boroughs, 2008; Boroughs, Cafri \&Thompson, 2005) to measure to what degree men observed that other men have depilated their body hair. The questions were as follows: 1) How often do you see (notice) other men at the gym that have removed or reduced their body hair?; 2) How often do you see (notice) other male friends that have removed or reduced their body hair?; 3) How often do you see (notice) other male classmates at school that have removed or reduced their body hair?; and 4) How often do you see (notice) other men anywhere else that have removed or reduced their body hair? These items had a scaled response set from $1=$ Never to $5=$ Always. More than $70 \%$ of the participants responded affirmatively to each of the four adjunct social comparison questions which were directly related to the men's observations of body depilation by other men. Mean scores indicate that men sometimes to frequently observe that other men have depilated their body hair at the gym $(M=2.5, S D=1.3)$, with friends $(M=2.4, S D=1.6)$, at school $(M=2.2, S D=1.1)$, and out in public $(\mathrm{M}=2.3, \mathrm{SD}=1.1)$. Sexual minority men reported higher levels of social comparison on each of the four aforementioned items with comparisons at school sexual minority men $(\mathrm{M}=2.6, \mathrm{SD}=1.3)$, compared to heterosexual men $(\mathrm{M}=2.2, \mathrm{SD}=1.1), F(1$, 
$297)=4.10, p=.045$, and out in public, sexual minority men $(\mathrm{M}=2.7, \mathrm{SD}=1.2)$, compared to heterosexual men $(\mathrm{M}=2.3, \mathrm{SD}=1.1), F(1,298)=4.43, p=.036$ being the observed statistically significant findings in the mean between group differences. These results supported the hypothesis that men who depilate their body hair are more likely to engage in physical appearance social comparison than those who do not.

Body depilation was not associated with the age of the participants. Men who engaged in body depilation ( $\mathrm{M}=20.9, \mathrm{SD}=4.1)$ were of equal age on average as nondepilators $(\mathrm{M}=20.8, \mathrm{SD}=3.7), t(350)=.282, p>.05$. Although more sexual minority men $(88.6 \%)$ were included among the group of body depilators when compared with heterosexual men (83\%), a series of chi-square tests indicated this was a non-significant relationship, $X^{2}=2.68, \mathrm{n} / \mathrm{s}$, therefore this hypothesis was not supported.

Using a scale of $1=$ no hair (or very little hair) to $5=$ very hairy, participants were asked about their body hair growth at specific body sites. Table 5 contains the data reflecting men's body hair growth with the three main sites for most men being the armpits $(\mathrm{M}=3.18, \mathrm{SD}=.95)$, groin $(\mathrm{M}=3.37, \mathrm{SD}=1.02)$, and legs $(\mathrm{M}=3.31, \mathrm{SD}=.99)$. Median data were also included, along with the percentage of men reporting little or no hair at a particular body site. A logistic regression was calculated to measure the predictive relationship between the level of body hair at the 12 body sites, and the likelihood of body depilation at those sites. Body depilation was significantly predicted by $X^{2}(343,12)=28.31, p=.005$ greater amounts of body hair growth at the following three body sites: groin/pubic hair (odds ratio=1.7, $p=.006$ ), the back of the neck (odds ratio $=1.5, p=.04$ ), and the buttocks (odds ratio=.61, $p=.02$ ). Table 5 shows the percentage of no hair growth by body site along with the odds ratios and $95 \%$ confidence intervals 
for the univariate logistic regression analysis. These results indicated that men with greater amounts of body hair at the groin/pubic area and neck were $70 \%$ and $48 \%$ more likely to depilate while greater buttock hair resulted in a $61 \%$ likelihood of not depilating given the negative $b$-weight of $-4.77, p=.023$ for the buttocks.

Table 5. Odds Ratios of Depilation by Body Site in Relation to Self-Reported Hair Growth by Site and Body Depilation Status

\begin{tabular}{llllll}
\hline & Body Site & $\begin{array}{c}\text { \% little or no } \\
\text { hair }\end{array}$ & Odds Ratio & $95 \%$ CI & P-value \\
\hline 1. & Neck & 56.5 & 1.48 & $1.02-2.14$ & $.040^{*}$ \\
2. & Shoulder & 74.2 & .849 & $.45-1.62$ & .620 \\
3. & Armpits & 4.5 & .824 & $.55-1.23$ & .342 \\
4. & Chest & 32.9 & 1.07 & $.70-1.65$ & .754 \\
5. & Abdomen & 24.6 & .819 & $.51-1.32$ & .414 \\
6. & Groin & 4.5 & 1.70 & $1.16-2.49$ & $.006^{* *}$ \\
7. & Back & 61.9 & 1.36 & $.79-2.32$ & .269 \\
8. & Buttocks & 28.4 & .614 & $.41-.93$ & $.021^{*}$ \\
9. & Arms & 16.4 & .842 & $.53-1.33$ & .458 \\
10. & Hands & 47.4 & 1.06 & $.63-1.78$ & .823 \\
11. & Legs & 3.3 & .997 & $.66-1.51$ & .989 \\
12. & Feet & 37.4 & .664 & $.42-1.06$ & .085 \\
\hline & & & & $* p<.05$ & $* * 01$ \\
\end{tabular}

A Pearson correlation was conducted to determine if an association exists between body depilation and hair growth by body site. This procedure was calculated by creating a composite score of the hair growth at all 12 body sites, and a composite score of total number of body sites where depilation took place. Body depilation was positively correlated, $r(202)=.224, p=.001$, with hair growth by body site. Men who reported having hair at a greater number of body sites, or a greater amount of hair at each site, were more likely to engage in body depilation.

Table 6 contains the results from the analysis of the Drive for Muscularity Scale for the sample. There were notable differences found on the scale scores with heterosexual men $(\mathrm{M}=2.6, \mathrm{SD}=1.11)$ having a greater level of Muscle Development Behaviors when compared with sexual minority men $(\mathrm{M}=1.97, \mathrm{SD}=1.06), F(1,358)=$ 
12.22, $p=.001$. In addition, racial/ethnic differences were discovered on the DMS, with Asian American men $(\mathrm{M}=3.74, \mathrm{SD}=1.33)$ having significantly greater drive on the Muscularity-Oriented Body Image Attitudes subscale, when compared with African American Men $(\mathrm{M}=2.98, \mathrm{SD}=1.02), F(4,347)=2.4, p=.05$. Though the drive for muscularity on this subscale was higher for Asian American participants compared to all other ethnicities (African American, Latino, Native American, and Euro American), only the difference between Asian Americans and African Americans was statistically significant as demonstrated through the Bonferroni post-hoc analysis. See Table 6 for means and standard deviations for each of the 15 items contained within the Drive for Muscularity Scale (McCreary \& Sasse, 2000).

Table 6. Drive for Muscularity Scale Mean and Standard Deviations

\begin{tabular}{llcc}
\hline Item & & M & SD \\
\hline 1. & I wish that I were more muscular. & 4.01 & 1.26 \\
2. & I lift weights to build up muscle. & 3.72 & 1.56 \\
3. & I use protein or energy supplements. & 2.72 & 1.69 \\
4. & I drink weight-gain or protein shakes. & 2.43 & 1.65 \\
5. & I try to consume as many calories as I can in a day. & 2.20 & 1.47 \\
6. & I feel guilty if I miss a weight-training session. & 2.69 & 1.57 \\
7. & I think I would feel more confident if I had more muscle mass. & 3.51 & 1.50 \\
8. & Other people think I work out with weights too often. & 1.79 & 1.14 \\
9. & I think that I would look better if I gained 10 pounds in bulk. & 3.13 & 1.73 \\
10. & I think about taking anabolic steroids. & 1.48 & 1.10 \\
11. & I think that I would feel stronger if I gained a little more muscle & 3.60 & 1.57 \\
& mass. & & \\
12. & I think that my weight-training schedule interferes with other & 2.00 & 1.30 \\
& aspects of my life. & 3.48 & 1.47 \\
13. & I think that my arms are not muscular enough. & 3.58 & 1.17 \\
14. & I think that my chest is not muscular enough. & 3.05 & 1.57 \\
15. & I think that my legs are not muscular enough. \\
\hline
\end{tabular}

An independent samples t-test was conducted to test the relationship between men's drive for muscularity and body depilation. Men who engage in body depilation $(\mathrm{M}=2.94, \mathrm{SD}=.94)$ had a higher drive for muscularity than non-depilators $(\mathrm{M}=2.62$, $\mathrm{SD}=.88), t(353)=2.33, p=.02$. This result supports the hypothesis that men who have a 
greater drive for muscularity are more likely to engage in body depilation than men with lower drive for muscularity.

An Independent samples t-test was conducted to examine the relationship between Body Depilation and the possible diagnosis of Body Dysmorphic Disorder (BDD). Thirteen cases were removed because of participant failure to answer any of the items on this scale. Of the remaining 347 participants, imputations were made for one case on some items, and up to the maximum of 9 cases on item 7 . Two t-tests were conducted with this scale. Men who engage in body depilation $(\mathrm{M}=37.22, \mathrm{SD}=25.17)$ were no more likely to have self-reported clinical levels of BDD than non-depilators ( $M=32.80$, $\mathrm{SD}=26.64), t(341)=1.20, p>.05$. Conversely, to explore the data with this scale further, an analysis of sexual orientation differences was undertaken. Sexual minority men $(\mathrm{M}=50.0, \mathrm{SD}=29.39)$ had statistically significant higher scores on the BDDE-SR when compared to heterosexual men $(\mathrm{M}=34.60, \mathrm{SD}=24.29), t(345)=-3.82, p<.000$.

In addition, a Pearson correlation was conducted to measure the association with the amount of body hair men reported and body dysmorphic symptomatology. A positive correlation between amount of body hair and BDDE-SR total score was observed, $r(334)$ $=.255, p<.000$. The sample average on the BDDE-SR was $(\mathrm{M}=36.55, \mathrm{SD}=25.47)$ which closely matches the scores reported for a normal population of men outlined by the instrument's authors (Rosen \& Reiter, 1996). With a potential proposed clinical cut-off score of " 66 " on this measure, $83.9 \%$ of the sample of men fell at or below this cut-off, and just $2 \%$ had total scores of "99" or above. Scores in this range are notable because they were derived from a clinical treatment group (Rosen \& Reiter, 1996). 
The relationship between body depilation and both appearance evaluation and body dissatisfaction (MBSRQ-AES \& BASS; Brown, Cash, \& Mikula, 1990) was tested. Independent samples t-tests were conducted revealing no statistically significant differences on these measures. Men who engaged in body depilation had higher body areas satisfaction $(M=35.7, S D=6.8)$ and greater appearance evaluation $(M=25.3$, $\mathrm{SD}=5.5)$ when compared to non-depilators $(\mathrm{M}=34.9, \mathrm{SD}=7.2$, and $\mathrm{M}=24.2, \mathrm{SD}=5.8$ respectively), $\mathrm{n} / \mathrm{s}$. This arrangement was reversed for the item added to the BASS subscale which measured the level of satisfaction with "Body Hair (amounts, locations, and coarseness)" where it was found that non-depilators ( $\mathrm{M}=3.53, \mathrm{SD}=1.26)$ were more satisfied with their body hair on average than men who engage in body depilation $(\mathrm{M}=3.44, \mathrm{SD}=1.12), t(348)=.535, p>.05$, though this difference was not statistically significant.

This additional item to the BASS sub-scale, which measured satisfaction with the amount, locations, and coarseness of body hair also had a negative correlation with the number of body sites that were depilated, $r(207)=-.189, p=.006$. Although no significant differences were observed between heterosexual and sexual minority men on either the composite total of the Appearance Evaluation Scale or the seven items within the scale, further analyses were undertaken to investigate racial/ethnic differences. Differences by race/ethnicity were observed for the total composite score, and on 5 of the 7 subscale items, and the observed differences demonstrated that African American men had higher scores on the (see Table 7). 
Table 7. Ethnic Differences on the Appearance Evaluation Scale

\begin{tabular}{|c|c|c|c|c|c|c|}
\hline & & $\begin{array}{l}\text { African } \\
\text { American }\end{array}$ & Asian American & Latino & $\begin{array}{l}\text { Native } \\
\text { American }\end{array}$ & $\begin{array}{l}\text { Euro } \\
\text { American }\end{array}$ \\
\hline 1. & My body is sexually appealing. & $3.84 *$ & $3.22 *$ & 3.53 & 4.00 & 3.56 \\
\hline 2. & I like my looks just the way they are. & $3.95 * *$ & $2.97 * *$ & 3.76 & 3.50 & $3.43 * *$ \\
\hline 3. & $\begin{array}{l}\text { Most people would consider me good } \\
\text { looking. }\end{array}$ & 3.88 & 3.54 & 3.78 & 3.50 & 3.64 \\
\hline 4. & I like the way I look without my clothes. & $3.93 * *$ & $2.86 * *$ & 3.49 & 3.50 & $3.26 * *$ \\
\hline 5 . & I like the way my clothes fit me. & $4.09 * *$ & $3.14 * *$ & 3.58 & 3.67 & $3.64 * *$ \\
\hline 6. & I dislike my physique. & $3.84 *$ & $3.11 *$ & 3.65 & 3.17 & 3.50 \\
\hline 7. & I'm physically unattractive. & 4.10 & 3.59 & 4.22 & 3.83 & 4.01 \\
\hline 8. & MSBRQ-AES total composite score & $27.53 * *$ & $22.35 * *$ & 25.86 & 25.17 & 25.02 \\
\hline
\end{tabular}

An independent samples t-test was computed to determine whether men who depilate their body hair $(\mathrm{M}=134.58, \mathrm{SD}=28.37)$ had greater levels of gender role conflict compared to non-depilators $(\mathrm{M}=130.44, \mathrm{SD}=30.42), t(348)=.996, p>.05$, the results were not statistically significant. In addition, a Pearson correlation was computed to measure the influence of gender-role conflict and its association with men's body depilation behaviors. This was tested by measuring the correlation between the total GRCS score, and number of body sites depilated. A statistically significant positive correlation was observed, $r(207)=.164, p=.018$ indicating that men who engaged in depilation of a greater number of body sites had higher levels of gender role conflict.

The results from Study 1 revealed the highest prevalence of body depilation by men to date $(83 \%)$. Although several hypotheses were not supported, others such as those related to greater levels of social comparison by men who engage in body depilation along with a higher drive for muscularity by those that depilate did find support from the data that were collected. 


\section{Chapter Four}

\section{STUDY 2}

The goal of Study 2 was to collect data from female participants to measure their attitudes toward men's body hair and toward body depilation by men. A 24-item scale was developed for this project. Previous research has shown that some women have a preference for trunk hair on men regardless of body shape (Dixson et al., 2003) while another study found that women rated hairless male bodies as most attractive with a steady decline in attractiveness reported as the men's bodies became more hirsute (Dixson et al., 2007). With a paucity of research reflecting women's attitudes toward body hair on men, and given the research indicating that a substantial number of men remove or reduce their body hair (Boroughs \& Thompson, 2002; Boroughs, Cafri, \& Thompson, 2005; Martins, Tiggemann, \& Churchett, 2008; Tiggemann, Martins, \& Churchett, 2008) a natural course for new research would be an investigation into women's attitudes toward both male body depilation along with their preferences for body hair on men.

\section{Method}

\section{Participants}

Study 2 included a sample of 723 female participants from a large southeastern American university that completed a measure on the topic of men's body hair along with a demographic questionnaire. The mean age of participants was $(M=20.97, S D=4.43)$, with $27.3 \%$ of the sample reporting the modal age of 18 . The majority of the sample 
(59.5\%) was Euro-American, with 17.7\% Latina, 15\% African American, 6\% Asian American, and $1.7 \%$ Native American. A majority of the sample (93.2\%) was socialized (grew-up) in the United States, and indicated a marital status of single (91.2\%).

Educational attainment was variable across college years with $12.7 \%$ having completed a high school diploma but not yet having completed the first year of college, $23.9 \%$ freshman, $15.5 \%$ sophomores, $24.8 \%$ juniors, and $22.3 \%$ seniors. Less than $1 \%$ of the sample was graduate students. The majority of the sample was heterosexual (94.5\%), with $3.6 \%$ indicating a bisexual orientation, and $1.9 \%$ indicating they identified as lesbian.

\section{Procedure}

Data were collected via SONA Systems at the University of South Florida. This is a system set up within the USF Department of Psychology to remunerate students with extra credit points for research participation. Students elect to sign-up to be a part of the SONA System at the beginning of each semester. Only those students who completed the "Mass Testing Survey", a screener, were eligible to participate in this study. The study was listed as "The Body Image Study" so that the name of the study did not prime participants as to the nature of the questions they would be asked about men's body depilation.

Female participants, regardless of sexual orientation, reported on their attitudes about body hair on men, as well as attitudes toward men's body depilation as part of Study 2. Sexual minority men, whose data were collected as a part of Study 1, also completed the same scale as female participants in this study on the topic of men's body hair. These sexual minority male participants were asked to serve as informants about 
their attitudes toward body hair on other men and on their attitudes toward body depilation by [other] men.

Measures

Attitudes Toward Body Hair on Men (ATBHM; Boroughs, 2008)

Developed for use with this research project, and inspired by a previous set of 13 similar questions used with men and women to measure attitudes about women's body hair (see Basow \& Braman, 1998), the Attitudes Toward Body Hair on Men Questionnaire (Boroughs, 2008) is a 24-item measure which utilizes a 5-point Likert scale to measure women and sexual minority men's agreement with a series of statements concerning body hair on men, and body depilation practices by men (see Appendices).

Although there were originally 729 female participants screened-in for Study 2, six participants were dropped because none of the items for the ATBHM instrument were completed. Mean imputation was used for the remaining participants $(\mathrm{N}=723)$. The imputations using mean values were as follows: items 2, 10, 17 and 24 (one imputation), items 3, 4, 7, 8, and 9 (two imputations), items 6 and 13 (three imputations), items 11 and 18 (four imputations), item 16 (five imputations), item 20 (six imputations), and items 1, $5,14,15,19,21,22$, and 23 did not have any missing data. 


\section{Chapter Five}

\section{Results and Discussion}

In order to determine whether any differences exist between heterosexual and sexual minority women, a one-way ANOVA was conducted to measure mean differences on the 24-item ATBHM scale. Seven of the 24 items yielded statistically significant mean differences between heterosexual and sexual minority women. Average scores were higher for heterosexual women on items $1,2,6$, and 15 which indicates that heterosexual women agree more strongly than sexual minority women that body hair is attractive on men, $F(1,720)=7.84, p=.005$, that the absence of body hair feminizes men, $F(1$, $720)=12.62, p<.000$, that men who depilate should receive social disapproval, $F(1$, $720)=5.84, p=.016$, and that body hair makes men look more mature, $F(1,720)=4.52, p$ $=.015$. Sexual minority women, by contrast, agreed more strongly with items 4,11 , and 14. This suggests that they agree that body hair on men is disgusting, $F(1,720)=5.23$, $p=.022$, that body hair makes men look like animals, $F(1,720)=12.82, p<.000$, and that body hair on men is ugly, $F(1,720)=7.29, p=.007$. These results indicate greater acceptance, and perhaps even preference for male hirsuteness by heterosexual women when compared to either bisexual or lesbian women. These results are listed with means and standard deviations for significant findings in Table 8. 
Table 8. Mean differences by Sexual Orientation on the ATBHM scale.

\begin{tabular}{|c|c|c|c|c|c|}
\hline Item & & $\begin{array}{l}\text { Heterosexual } \\
\mathrm{M} \text { (SD) }\end{array}$ & $\begin{array}{l}\text { Sexual minority } \\
\text { M (SD) }\end{array}$ & $F$ & $p$-Value \\
\hline 1. & Body hair on men is attractive. & $2.85(1.04)$ & $2.38(1.10)$ & 7.84 & .005 \\
\hline 2. & Lack of body hair makes men look like women. & $2.28(1.02)$ & $1.70(.85)$ & 12.6 & .000 \\
\hline 4. & Body hair on men is disgusting. & $2.83(1.04)$ & $3.22(1.19)$ & 5.23 & .022 \\
\hline 6. & $\begin{array}{l}\text { Men who remove or reduce their body hair should } \\
\text { receive social disapproval. }\end{array}$ & $1.79(.82)$ & $1.48(.72)$ & 5.84 & .016 \\
\hline 11. & Body hair makes men look like animals. & $2.47(.98)$ & $3.05(1.11)$ & 12.8 & .000 \\
\hline 14. & Body hair on men is ugly. & $2.60(1.01)$ & $3.05(1.28)$ & 7.29 & .007 \\
\hline 15. & Body hair makes men look mature. & $3.35(.87)$ & $3.00(1.01)$ & 5.92 & .015 \\
\hline
\end{tabular}

Despite the observed differences between the heterosexual and sexual minority

women on several items contained within the scale, a series of Exploratory Factor

Analyses (EFA) were conducted with the entire sample as well as separately for

heterosexual women, and sexual minority women. The factor structure was not affected

by this split, so it was decided to keep all participants in the analyses regardless of sexual orientation to maintain sample variability. Therefore all factor analysis results will be reported for the entire sample $(\mathrm{N}=723)$.

Factor Analysis

An exploratory factor analysis was conducted to examine the structure of the ATBHM scale which was developed for this research project. The proposal called for Principal Axis Factoring with Varimax Rotation, though several alternative models were also looked at including a Principle Components Analysis with Varimax and Promax rotations. Upon review of the factor loadings, multiple rotations, and various interpretations of the data, a 5-Factor orthogonal solution was originally extracted. This model was problematic because although 23 of the 24 items surpassed the minimum .40 factor loading (only item 10 fell below this threshold loading at .399), several of the items cross-loaded onto other factors, and had weak (minimal) factor loadings. It was therefore decided to eliminate four items $(2,9,10$, and 20), and proceed with another EFA to examine the factor structure of the remaining 20 items. Table 9 contains all of the 
originally proposed items of the Attitudes Toward Body Hair on Men scale that were developed for this study. Each of the not yet named Factors appear across the top of the table and factor loadings appear under each factor (F1, F2, F3, F4 and F5) representative of the original 5-Factor solution.

Table 9. Factor Pattern Coefficients of the ATBHM scale from a Principal Axis Factor Analysis with Orthogonal Rotation (original)

\begin{tabular}{|c|c|c|c|c|c|}
\hline Item & F1 & $\mathrm{F} 2$ & F3 & $\mathrm{F} 4$ & F5 \\
\hline 1. Body hair on men is attractive. & -.636 & .422 & -.186 & .178 & -.001 \\
\hline 2. Lack of body hair makes men look like women. & .158 & -.344 & .040 & -.441 & -.057 \\
\hline 3. Men should remove back hair. & .334 & -.012 & .175 & -.175 & .635 \\
\hline 4. Body hair on men is disgusting. & .767 & -.273 & .180 & -.001 & .201 \\
\hline 5. Body hair on men feels physically uncomfortable. & .753 & -.180 & .163 & .002 & .131 \\
\hline $\begin{array}{l}\text { 6. Men who remove or reduce their body hair should receive social } \\
\text { disapproval. }\end{array}$ & .033 & .130 & -.033 & 613 & -.049 \\
\hline 7. Men's bodies are okay unshaved. & -.211 & .444 & -.073 & -.028 & -.223 \\
\hline 8. Body hair is masculine. & -.270 & 680 & -.057 & .041 & .055 \\
\hline 9. Men need to remove or reduce body hair in order to appeal to others. & -.411 & .247 & -.194 & -.231 & -.371 \\
\hline 10. Body Hair removal or reduction makes men's skin feel stubbly. & .046 & .399 & .031 & .110 & .001 \\
\hline 11. Body hair makes men look like animals. & .521 & -.126 & .160 & .247 & .179 \\
\hline 12. Removing or reducing body hair signals that a man is a "metrosexual". & .035 & .258 & -.027 & .557 & -.028 \\
\hline 13. Removing or reducing body hair signals that a man is gay. & -.002 & .003 & -.131 & .771 & -.080 \\
\hline 14. Body hair on men is ugly. & .683 & -.333 & .189 & .088 & .228 \\
\hline 15. Body hair makes men look mature. & -.181 & .552 & -.050 & .117 & .088 \\
\hline 16. Men should reduce or remove their body hair to look more muscular. & .276 & -.206 & .489 & .228 & .288 \\
\hline 17. Back hair on men is disgusting. & .464 & .054 & .249 & -.093 & .524 \\
\hline 18. Men who remove or reduce their body hair look cleaner. & .521 & .018 & .472 & -.207 & .269 \\
\hline $\begin{array}{l}\text { 19. Hairy men should remain hairy, and naturally smooth men should } \\
\text { remain smooth. }\end{array}$ & -.095 & .454 & -.115 & .185 & -.264 \\
\hline 20. Body hair on men feels good. & .476 & -.393 & .180 & -.261 & .103 \\
\hline 21. Chest hair on men is masculine. & -.276 & .593 & -.095 & .128 & -.062 \\
\hline 22. Men look more muscular without body hair. & .148 & -.119 & .806 & -.092 & .089 \\
\hline 23. Men appear more defined (cut) without body hair. & .190 & -.035 & .819 & -.092 & .079 \\
\hline 24. Men look cleaner without body hair. & .488 & -.035 & .583 & -.233 & .131 \\
\hline
\end{tabular}

The second EFA, using principal axis factoring with an orthogonal rotation, produced a four factor solution. The previous two items that loaded onto the fifth factor now load onto Factor 1. Table 10 contains the factor pattern coefficients of the ATBHM scale without the four eliminated items $(2,9,10$, and 20). This rotation allowed all of the items on the scale to surpass the minimum .40 factor loading and both the eigenvalue $\geq 1$, and Scree Plot methods of evaluation suggest this is a good fit for the data. This 
extraction of 4-Factors was decidedly the best both theoretically and statistically despite a few items that cross-loaded onto other factors with one exception. Item 19 was dropped from the scale, leaving a total of 19-items for the final scale. The final factor loadings appear in Table 10 in bold.

Table 10. Factor Pattern Coefficients of the ATBHM scale from a Principal Axis Factor Analysis with Orthogonal Rotation (Final)

\begin{tabular}{|c|c|c|c|c|}
\hline Item & F1 & $\mathrm{F} 2$ & F3 & $\mathrm{F} 4$ \\
\hline 1. Body hair on men is attractive. & -.464 & .565 & -.176 & .101 \\
\hline 3. Men should remove back hair. & .600 & -.035 & .163 & -.187 \\
\hline 4. Body hair on men is disgusting. & .700 & -.463 & .153 & .050 \\
\hline 5. Body hair on men feels physically uncomfortable. & .645 & -.375 & .145 & .058 \\
\hline $\begin{array}{l}\text { 6. Men who remove or reduce their body hair should receive social } \\
\text { disapproval. }\end{array}$ & -.014 & .105 & -.028 & .601 \\
\hline 7. Men's bodies are okay unshaved. & -.223 & .428 & -.066 & .009 \\
\hline 8. Body hair is masculine. & -.081 & .736 & -.057 & .035 \\
\hline 11. Body hair makes men look like animals. & .500 & -.246 & .139 & .268 \\
\hline 12. Removing or reducing body hair signals that a man is a "metrosexual". & .027 & .236 & -.020 & .579 \\
\hline 13. Removing or reducing body hair signals that a man is gay. & -.085 & -.005 & -.116 & .795 \\
\hline 14. Body hair on men is ugly. & .648 & -.471 & .163 & .133 \\
\hline 15. Body hair makes men look mature. & -.010 & .598 & -.053 & .114 \\
\hline 16. Men should reduce or remove their body hair to look more muscular. & .359 & -.224 & .464 & .194 \\
\hline 17. Back hair on men is disgusting. & .685 & -.011 & .222 & -.092 \\
\hline 18. Men who remove or reduce their body hair look cleaner. & .609 & -.087 & .444 & -.175 \\
\hline $\begin{array}{l}\text { 19. Hairy men should remain hairy, and naturally smooth men should remain } \\
\text { smooth. }\end{array}$ & -.159 & .386 & -.112 & .221 \\
\hline 21. Chest hair on men is masculine. & -.163 & 638 & -.092 & .129 \\
\hline 22. Men look more muscular without body hair. & .186 & -.140 & .807 & -.088 \\
\hline 23. Men appear more defined (cut) without body hair. & .231 & -.083 & .810 & -.092 \\
\hline 24. Men look cleaner without body hair. & .500 & -.145 & .554 & -.189 \\
\hline
\end{tabular}

As mentioned, four factors were extracted from the second PAF. Five items (1, $14,16,19$, and 24) were questionable. It was decided to drop only one item (19), due to weak loadings, but leave the other items for the full scale if not for a particular factor. Proposed factors names are as follows: Factor 1 (Body Hair Disgust) items 3, 4, 5, 11, 14, 17, 18; Factor 2 (Masculinity) items 1, 7, 8, 15, 21; Factor 3 (Muscularity) items 16, 22, 23, 24, and Factor 4 (Social Feedback) items 6, 12, 13.

In order to further examine the reliability of the factor structure, a series of reliability estimates were run for the full scale, and for each of the four factors. 


\section{Reliability Estimates}

Cronbach's alphas were computed for the entire scale with a total of 19-items, $\alpha=$ .65 , as well as for each of the four factors. Table 11 contains the item to total correlations

for the full scale.

Table 11. Item to total correlations for the ATBHM full scale $\alpha=.65$

\begin{tabular}{|c|c|c|c|c|c|c|}
\hline & Item & $\begin{array}{c}\text { Scale } \\
\text { Mean if } \\
\text { Item } \\
\text { Deleted }\end{array}$ & $\begin{array}{c}\text { Scale } \\
\text { Variance } \\
\text { if Item } \\
\text { Deleted }\end{array}$ & $\begin{array}{l}\text { Corrected } \\
\text { Item-Total } \\
\text { Correlation }\end{array}$ & $\begin{array}{l}\text { Squared } \\
\text { Multiple } \\
\text { Correlation }\end{array}$ & $\begin{array}{l}\text { Cronbach's } \\
\text { Alpha if } \\
\text { Item } \\
\text { Deleted }\end{array}$ \\
\hline 1. & Body hair on men is attractive. & 54.23 & 52.325 & -.389 & .559 & .715 \\
\hline 3. & Men should remove back hair. & 53.27 & 40.825 & .408 & .455 & 619 \\
\hline 4. & Body hair on men is disgusting. & 54.20 & 40.396 & .447 & 697 & .614 \\
\hline 5. & Body hair on men feels physically uncomfortable. & 54.21 & 40.311 & .440 & .594 & 615 \\
\hline 6. & $\begin{array}{l}\text { Men who remove or reduce their body hair should } \\
\text { receive social disapproval. }\end{array}$ & 55.28 & 45.556 & .119 & .306 & .654 \\
\hline 7. & Men's bodies are okay unshaved. & 53.58 & 48.934 & -.177 & .232 & 685 \\
\hline 8. & Body hair is masculine. & 53.71 & 47.354 & -.051 & .440 & 673 \\
\hline 11. & Body hair makes men look like animals. & 54.56 & 40.829 & .446 & .399 & .616 \\
\hline 12. & $\begin{array}{l}\text { Removing or reducing body hair signals that a } \\
\text { man is a "metrosexual". }\end{array}$ & 54.72 & 44.248 & .154 & .308 & .653 \\
\hline 13. & $\begin{array}{l}\text { Removing or reducing body hair signals that a } \\
\text { man is gay. }\end{array}$ & 55.41 & 46.409 & .035 & .441 & .662 \\
\hline 14. & Body hair on men is ugly. & 54.44 & 40.576 & .446 & .644 & .615 \\
\hline 15. & Body hair makes men look mature. & 53.73 & 46.426 & .027 & .312 & .664 \\
\hline 16. & $\begin{array}{l}\text { Men should reduce or remove their body hair } \\
\text { to look more muscular. }\end{array}$ & 54.36 & 40.748 & .490 & .430 & 612 \\
\hline 17. & Back hair on men is disgusting. & 53.43 & 38.576 & .520 & .515 & 600 \\
\hline 18. & $\begin{array}{l}\text { Men who remove or reduce their body hair look } \\
\text { cleaner. }\end{array}$ & 53.41 & 40.458 & .529 & .628 & .608 \\
\hline 21. & Chest hair on men is masculine. & 53.90 & 48.169 & -.118 & .391 & 682 \\
\hline 22. & Men look more muscular without body hair. & 53.73 & 41.549 & .412 & .583 & .621 \\
\hline 23. & Men appear more defined (cut) without body hair. & 53.49 & 41.508 & .457 & 609 & 618 \\
\hline 24. & Men look cleaner without body hair. & 53.37 & 40.854 & .486 & .652 & .613 \\
\hline
\end{tabular}

The alpha for Factor 1 (Body Hair Disgust) of the ATBHM scale was .87. The Cronbach's alpha was sufficient and all items were retained for this factor. Table 12 contains the item to total correlations for the 7-items of Factor 1. 
Table 12. Item to total correlations for Factor 1 of the ATBHM scale $\alpha=.87$

\begin{tabular}{|c|c|c|c|c|c|c|}
\hline & Item & $\begin{array}{c}\text { Scale } \\
\text { Mean if } \\
\text { Item } \\
\text { Deleted }\end{array}$ & $\begin{array}{c}\text { Scale } \\
\text { Variance } \\
\text { if Item } \\
\text { Deleted } \\
\end{array}$ & $\begin{array}{c}\text { Corrected } \\
\text { Item-Total } \\
\text { Correlation }\end{array}$ & $\begin{array}{c}\text { Squared } \\
\text { Multiple } \\
\text { Correlation }\end{array}$ & $\begin{array}{c}\text { Cronbach's } \\
\text { Alpha if } \\
\text { Item } \\
\text { Deleted } \\
\end{array}$ \\
\hline \multirow{3}{*}{$\begin{array}{l}3 . \\
4 . \\
5 .\end{array}$} & Men should remove back hair. & 18.09 & 23.160 & .546 & .414 & .859 \\
\hline & Body hair on men is disgusting. & 19.02 & 21.397 & .755 & .661 & .830 \\
\hline & $\begin{array}{l}\text { Body hair on men feels physically } \\
\text { uncomfortable. }\end{array}$ & 19.03 & 21.761 & 690 & .582 & .839 \\
\hline 11. & Body hair makes men look like animals. & 19.37 & 23.805 & .523 & .354 & .861 \\
\hline 14. & Body hair on men is ugly. & 19.25 & 21.891 & .718 & .590 & .835 \\
\hline 17. & Back hair on men is disgusting. & 18.25 & 21.669 & .628 & .499 & .848 \\
\hline 18. & $\begin{array}{l}\text { Men who remove or reduce their body hair } \\
\text { look cleaner. }\end{array}$ & 18.23 & 23.562 & .613 & .400 & .850 \\
\hline
\end{tabular}

The alpha for Factor 2 (Masculinity) of the ATBHM scale was .76. The

Cronbach's alpha was sufficient and all items were retained for this factor. Table 13

contains the item to total correlations for the 5-items of Factor 2.

Table 13. Item to total correlations for Factor 2 of the ATBHM scale $\alpha=.76$

\begin{tabular}{llccccc}
\hline & Item & $\begin{array}{c}\text { Scale } \\
\text { Mean if } \\
\text { Item } \\
\text { Deleted }\end{array}$ & $\begin{array}{c}\text { Scale } \\
\text { Variance } \\
\text { if Item } \\
\text { Deleted }\end{array}$ & $\begin{array}{c}\text { Corrected } \\
\text { Item-Total } \\
\text { Correlation }\end{array}$ & $\begin{array}{c}\text { Squared } \\
\text { Multiple } \\
\text { Correlation }\end{array}$ & $\begin{array}{c}\text { Cronbach's } \\
\text { Alpha if Item } \\
\text { Deleted }\end{array}$ \\
\hline 1. & Body hair on men is attractive. & 13.31 & 7.139 & .554 & .312 & .714 \\
7. & Men's bodies are okay unshaved. & 12.66 & 8.522 & .392 & .170 & .766 \\
8. & Body hair is masculine. & 12.79 & 7.417 & .634 & .409 & .686 \\
15. & Body hair makes men look mature. & 12.81 & 7.998 & .517 & .292 & .726 \\
21. & Chest hair on men is masculine. & 12.98 & 7.363 & .576 & .356 & .705 \\
\hline
\end{tabular}

The alpha for Factor 3 (Muscularity) of the ATBHM scale was .82. The Cronbach's alpha was sufficient and all items were retained for this factor. Table 14 contains the item to total correlations for the 4-items of Factor 3. 
Table 14. Item to total correlations for Factor 3 of the ATBHM scale $\alpha=.82$

\begin{tabular}{llccccc}
\hline & Item & $\begin{array}{c}\text { Scale } \\
\text { Mean if } \\
\text { Item } \\
\text { Deleted }\end{array}$ & $\begin{array}{c}\text { Scale } \\
\text { Variance } \\
\text { if Item } \\
\text { Deleted }\end{array}$ & $\begin{array}{c}\text { Corrected } \\
\text { Item-Total } \\
\text { Correlation }\end{array}$ & $\begin{array}{c}\text { Squared } \\
\text { Multiple } \\
\text { Correlation }\end{array}$ & $\begin{array}{c}\text { Cronbach's } \\
\text { Alpha if } \\
\text { Item } \\
\text { Deleted }\end{array}$ \\
\hline 16. & $\begin{array}{l}\text { Men should reduce or remove their } \\
\text { body hair to look more muscular. }\end{array}$ & 10.58 & 5.778 & .510 & .268 & .833 \\
22. $\quad \begin{array}{l}\text { Men look more muscular without } \\
\text { body hair. }\end{array}$ & 9.95 & 4.985 & .723 & .571 & .733 \\
$\quad \begin{array}{l}\text { Men appear more defined (cut) } \\
\text { without body hair. }\end{array}$ & 9.71 & 5.181 & .744 & .598 & .727 \\
24. & & & & .394 & .790 \\
\hline
\end{tabular}

The alpha for Factor 4 (Social Feedback) of the ATBHM scale was .69. The Cronbach's alpha was decidedly lower, but close to .70 and therefore sufficient and necessary to support the rest of scale theoretically. Therefore, all items were retained for this factor. Table 15 contains the item to total correlations for the 3-items of Factor 4.

Table 15. Item to total correlations for Factor 4 of the ATBHM scale $\alpha=.69$

\begin{tabular}{llccccc}
\hline & Item & $\begin{array}{c}\text { Scale } \\
\text { Mean if } \\
\text { Item } \\
\text { Deleted }\end{array}$ & $\begin{array}{c}\text { Scale } \\
\text { Variance } \\
\text { if Item } \\
\text { Deleted }\end{array}$ & $\begin{array}{c}\text { Corrected } \\
\text { Item-Total } \\
\text { Correlation }\end{array}$ & $\begin{array}{c}\text { Squared } \\
\text { Multiple } \\
\text { Correlation }\end{array}$ & $\begin{array}{c}\text { Cronbach's } \\
\text { Alpha if } \\
\text { Item } \\
\text { Deleted }\end{array}$ \\
\hline $6 . \quad \begin{array}{l}\text { Men who remove or reduce their body } \\
\text { hair should receive social disapproval. }\end{array}$ & 3.99 & 2.659 & .502 & .285 & .625 \\
$\begin{array}{l}\text { 12. } \\
\text { Removing or reducing body hair } \\
\text { signals that a man is a "metrosexual". }\end{array}$ & 3.42 & 2.087 & .477 & .237 & .681 \\
$\begin{array}{l}\text { 13. } \\
\text { Removing or reducing body hair } \\
\text { signals that a man is gay. }\end{array}$ & 4.12 & 2.399 & .589 & .356 & .518 \\
\hline
\end{tabular}

Table 16 contains the observed correlations between the four named factors of the ATBHM scale as well as the correlation between each factor and the full scale. Items producing the Body Hair Disgust Factor were negatively associated $(r=-.53, p<.001)$ with the Masculinity Factor, and $(r=-.08, p<.05)$ the Social Feedback Factor, but positively correlated $(r=.62, p<.001)$ with the Muscularity Factor. 
Table 16. Factor correlations of the ATBHM scale

\begin{tabular}{|c|c|c|c|c|c|c|}
\hline & Factor Name & 1 & 2 & 3 & 4 & 5 \\
\hline 1. & Body hair disgust & & $-.532 * *$ & $.616 * *$ & $-.082 *$ & $.775 * *$ \\
\hline 2. & Masculinity & & & $-.370 * *$ & $.222 * *$ & .025 \\
\hline 3. & Muscularity & & & & $-.135 * *$ & $.70 * *$ \\
\hline 4. & Social Feedback & & & & & $.298 * *$ \\
\hline 5. & Full Scale ATBHM & & & & & \\
\hline
\end{tabular}

The final scale included 19-items and four factors. On average, women disagreed that men's body hair is attractive $(\mathrm{M}=2.83, \mathrm{SD}=1.1)$, but also disagreed that body hair was either disgusting $(\mathrm{M}=2.85, \mathrm{SD}=1.1)$, or ugly $(\mathrm{M}=2.62, \mathrm{SD}=1.0)$. Women agreed that back hair is disgusting $(\mathrm{M}=3.62, \mathrm{SD}=1.2)$, and that men should remove it $(\mathrm{M}=3.8$, $\mathrm{SD}=.90$ ). Women did not agree that men who engage in body depilation should receive social disapproval $(\mathrm{M}=1.8, \mathrm{SD}=.81)$, or that they were gay $(\mathrm{M}=1.7, \mathrm{SD}=.85)$, or metrosexual $(\mathrm{M}=2.3, \mathrm{SD}=1.1)$. Table 17 contains the means, standard deviation and percentage "agree" or "strongly agree" for the final 19-items of the ATBHM scale. 
Table 17. Means, standard deviation, and percent agree for items on ATBHM scale

\begin{tabular}{|c|c|c|c|c|}
\hline & Item & Mean & SD & $\% \mathrm{~A}$ or $\mathrm{SA}$ \\
\hline 1. & Body hair on men is attractive. & 2.83 & 1.049 & 27.2 \\
\hline 3. & Men should remove back hair. & 3.79 & 1.066 & 65.3 \\
\hline 4. & Body hair on men is disgusting. & 2.85 & 1.057 & 26 \\
\hline 5. & Body hair on men feels physically uncomfortable. & 2.85 & 1.083 & 26.6 \\
\hline 6. & $\begin{array}{l}\text { Men who remove or reduce their body hair should receive social } \\
\text { disapproval. }\end{array}$ & 1.78 & .814 & 3.3 \\
\hline 7. & Men's bodies are okay unshaved. & 3.48 & .887 & 53.7 \\
\hline 8. & Body hair is masculine. & 3.35 & .901 & 46.1 \\
\hline 11. & Body hair makes men look like animals. & 2.50 & .999 & 17.3 \\
\hline 12. & Removing or reducing body hair signals that a man is a "metrosexual". & 2.34 & 1.055 & 16.3 \\
\hline 13. & Removing or reducing body hair signals that a man is gay. & 1.65 & .845 & 3.6 \\
\hline 14. & Body hair on men is ugly. & 2.62 & 1.034 & 19.4 \\
\hline 15. & Body hair makes men look mature. & 3.33 & .879 & 47.2 \\
\hline 16. & Men should reduce or remove their body hair to look more muscular. & 2.70 & .942 & 17.7 \\
\hline 17. & Back hair on men is disgusting. & 3.62 & 1.173 & 60.4 \\
\hline 18. & Men who remove or reduce their body hair look cleaner. & 3.65 & .923 & 63.5 \\
\hline 21. & Chest hair on men is masculine. & 3.15 & .971 & 38 \\
\hline 22. & Men look more muscular without body hair. & 3.33 & .954 & 46.3 \\
\hline 23. & Men appear more defined (cut) without body hair. & 3.57 & .888 & 60.4 \\
\hline 24. & Men look cleaner without body hair. & 3.68 & .934 & 65.8 \\
\hline F1 & Body Hair Disgust & 3.13 & .781 & \\
\hline $\mathrm{F} 2$ & Masculinity & 3.23 & 674 & \\
\hline F3 & Muscularity & 3.32 & .749 & \\
\hline $\mathrm{F} 4$ & Social Feedback & 1.92 & .719 & \\
\hline FS & Attitudes Toward Body Hair on Men & 3.00 & .363 & \\
\hline
\end{tabular}

In addition to the factor analyses and reliability analyses that were conducted for the ATBHM scale, a series of linear regressions were undertaken with the entire sample $(\mathrm{N}=723)$ as well as with the sample of heterosexual women alone $(\mathrm{N}=682)$ to test the research question that posited that gym attendance may be related to a preference for the hairless ideal on men. The model included five independent variables: 1) aerobic exercise in the gym, 2) aerobic exercise outside the gym, 3) anaerobic exercise in the gym, 4) anaerobic exercise outside the gym, and 5) the sum of all exercise variables. These five 
factors (independent variables) were tested against 9 individual items (dependent variables) from the ATBHM questionnaire that pertained to preference for either hairlessness on men's bodies, or a preference for men to depilate their extant body hair. Only these items were selected because they were expected to be indicative of bodily hairlessness and could be visually judged. This decided by experts and was thought to be superior to the inclusion of unrelated items from the ATBHM scale such as those items that require contact or other unrelated items such as those related to social feedback. In addition to the 9 selected items used to represent either a preference for hairlessness, or a preference for men to engage in body depilation to remove or reduce body hair, a composite score was created by summing these 9 -items which resulted in a total of 10 dependent variables that were tested in the regression model. All of these regressions were $\mathrm{n} / \mathrm{s}$, and therefore the frequency with which women participate in exercise activities both inside and outside of a gym is not related to their preference for the hairless male body ideal regardless of whether or not sexual minority women were include in the model.

This study reflects one of the contemporary approaches in use in men's body image research. By using the latest available measures, in this case a measure created specifically for use with this research question (ATBHM; Boroughs, 2008), a four-factor solution was extracted that both statistically and theoretically explained the observed data and addressed the substantive issue phenomenologically.

Like previous studies (see Dixson et al, 2003; Dixson et al, 2007; and Dixson et al., 2007), Study 2 measured women's attitudes toward men's body hair, but for the first time women's attitudes towards men's engagement in body depilation was measured. 
Heterosexual women had a more positive attitude towards body hair on men than sexual minority women. Although sexual minority women reported body hair (chest hair specifically) to be more related to masculinity, they were more tolerant in their attitudes toward body depilation by men, whereas heterosexual women endorsed more strongly the idea that men should receive social disapproval for body depilation. The one exception to this rule was that of "back hair" where the 2 items on this topic originally formed their own factor. Statistical considerations lead to removal of some items from the scale and that resulted in a shift of the "back hair" items on to another factor (Factor 1), which was eventually labeled "Body Hair Disgust". 


\section{Chapter Six}

\section{General Discussion}

Though body image research has traditionally focused on the concerns of females (Thompson, 1990), over the past two decades, researchers have endeavored to measure and explain the body image issues of both men and women. It is clear that while men have some overlap with women in their body image concerns, appearance concerns, and exercise attitudes, men also have some unique appearance issues (Boroughs \& Thompson, 2002; Boroughs, Cafri, \& Thompson, 2005; McCreary, Hildebrant, Heinberg, Boroughs \& Thompson, 2007; Thompson, Heinberg, Altabe, \& Tantleff-Dunn, 1999; Cafri \& Thompson, 2007). Starting about 15 years ago when Thompson and Tantleff (1992) found that men desired a larger and more muscular chest size than they currently possessed and further supported by the research of Pope, et al. (1997) who found that men's obsession with muscularity might approximate pathological levels after finding that a remarkable number of bodybuilders met criteria for Body Dysmorphic Disorder (BDD), researchers have since moved toward a bottom-up process in the creation of measures to investigate the body image concerns of men and next theoretical paradigms to explain the findings. This forever changed the model that relied on minor modifications to the wording of instruments already in use with women.

This research project reflects one of the contemporary approaches in use in the field of men's body image research. By using the latest available measures (e.g. DMS, McCreary \& Sasse, 2000; BoDeQ; Boroughs, Cafri, \& Thompson, 2005) and coupling 
these modern measures with an internet data collection strategy, large sample sizes were achieved which allowed for not only greater statistical power, but also the ability to conduct more complex analyses of the data. Many of the hypotheses included in this project hinged on the relationship of adjunct factors as they related to body image (e.g. gender role conflict, appearance evaluation) as predictors of body depilation. While several of the hypotheses were not supported by the data, this may well be attributed to the very high base rate of body depilation that was observed. To date, the prevalence estimate of body depilation reported in this study is the highest ever observed in men at $83.7 \%$ which is approximately $20 \%$ higher than previous reports (Boroughs \& Thompson, 2002; Boroughs, Cafri, \& Thompson, 2005) and is double, or even triple the rate more recently reported by Australian researchers (see Martins, Tiggemann, \& Churchett, 2008; and Tiggemann, Martins, \& Churchett, 2008). It is unclear at this time if this high base rate is related to an increase in the behavior, or simply an artifact of better methodologies being used to collect the data. The higher than expected base rate makes the prediction of body depilation through ancillary variables rather difficult.

Nevertheless, several key hypotheses were supported. For example, men overwhelmingly endorsed statements suggesting that Social Comparison Theory is a viable explanation for the proliferation of body depilation among men. Men who engaged in body depilation had statistically significant higher average scores on a measure of physical appearance comparison (PACS; Thompson, Heinberg, \& Tantleff, 1991). Most men (75\%) that were part of the body depilation group also affirmatively endorsed several statements related to their observations that other men had depilated in several different social spheres including friends, classmates, gym mates, and unknown 
strangers. Although sexual minority men differed significantly with their social observations, heterosexual men still reported observing that others depilated from frequently to sometimes in all of the noted social spheres. The concern that men may fear admitting to social comparison on issues surrounding their body image because of fear of being labeled gay was not supported by the observed results.

Other hypotheses that were supported include the correlation between hair growth by body site and depilation behaviors reported at those sites $(r=.224, p=.001)$, so the more hirsute a man is, the more likely it is that he will depilate his body hair. A relationship between the drive for muscularity and body depilation was found where depilators $(\mathrm{M}=2.9)$ had a higher drive for muscularity than non-depilators $(\mathrm{M}=2.3)$, $t(353)=2.33, p=.02$, therefore, those men that depilate their body hair have a higher drive for muscularity. Though unclear as to whether the drive for muscularity precedes or follows body depilation, this key issue has not been studied before. Though gym attendance was not associated with body depilation, clearly the desire for greater muscularity is.

In addition, heterosexual men were shown to have a greater drive for muscularity than sexual minority men, and Asian men were shown to have greater drive than other ethnicities. This finding on Asian American men's drive for muscularity was congruent with the findings measured in this study on body image disturbance where Asian American men reported lower appearance satisfaction, and less body site satisfaction than the other ethnicities measured.

Surprisingly, African American men reported the highest levels of body areas satisfaction and appearance evaluation suggestive of some protective factors that may be 
at work. Heterosexual men also reported greater levels of body areas satisfaction and appearance evaluation compared with sexual minority men, and sexual minority men $(\mathrm{M}=50)$ had statistically significant higher scores on a measure of BDD than heterosexual men $(M=35)$ a finding that would be an additional body image risk factor for gay and bisexual men who already have a reportedly higher level of eating disturbance (see Boroughs \& Thompson, 2002; Yelland \& Tiggemann, 2003; Duggan \& McCreary, 2004; Kimmel \& Mahalik, 2005). Though significant differences were not observed between heterosexual (83\%) and sexual minority men (88\%) on body depilation in this study, other studies have documented differences across the sexual orientations (Martins et al., 2008).

Psychological health implications were measured along with physical injuries that men sustained as a result of their depilating their body hair. Epidemiological studies have identified clustered outbreaks of treatment resistant Staphylococcus Infections in athletes in both college (Begier, et al., 2004) and professional sports (Miller et al., 2007). These infections are directly associated with body depilation and subsequent "turf burns" or use of towels or whirpools that athletes share in the course of their practice and/or games (Begier et al., 2004; Miller et al., 2007). Porche (2007) suggested that healthcare providers screen for male body depilation and educate them about the risks of infection. Clearly the youngest generation of men who engage in body depilation (the mean age of this sample was 20.9 years and the modal age 18 years) potentially grew-up with the prospect of trying this behavior as it was already trumpeted in the media (Gomes, 2001; Smith, 2000; Stuever, 2000; Stein, 1999; Schuler, 2000; and Simpson, 1994, 2002) and the scientific literature (Boroughs \& Thompson, 2002) by the time their age cohort 
entered puberty. The area of psychological and physical health implications as they relate to body depilation is ripe for further scientific inquiry.

This study was not only the first to measure self-reported body hair growth across 12 distinct body sites, but was also the first investigation in women's attitudes toward men's engagement in body depilation. A measure was created for this study that also included items that asked women about their attitudes towards men's body hair (ATBHM; Boroughs, 2008). Heterosexual women had a more positive attitude towards body hair on men than sexual minority women. Although sexual minority women reported body hair (chest hair specifically) to be more related to masculinity, they were more tolerant of body depilation by men, whereas heterosexual women endorsed more strongly the idea that men should receive social disapproval for body depilation. The one exception to this rule was "back hair" where items on this topic were originally extracted onto their own factor during the course of the first factor analysis. Perhaps sexual minority women's acceptance of body depilation and preference for hairlessness in men relates to their same-sex attractions in a culture where women's body depilation is strongly normative (Basow \& Braman, 1998; Hope, 1982; Tiggemann \& Kenyon, 1998; Toerien \& Wilkinson, 2003, 2004).

Limitations exist with this study including the small sample size of both sexual and racial/ethnic minorities. A related limitation is the measurement of human sexuality in the context of body image research and the implications of asking participants about their orientation, attraction or both when trying to learn about how this may affect their ratings of attractiveness or social comparison. While the internet technology utilized in this study may provide for some challenges and limitations, most of the traditional 
limitations of research were not problematic. For example, although there was missing data observed for several participants in this study, very few cases required imputation, and even fewer cases were lost to listwise deletions. The sample size for the majority of analyses that were conducted was robust. A strength of the study, perhaps realized best through the support for Social Comparison Theory as a paradigm to explain body depilation, is that like any body image study, the confidential nature of the data collection via personal computers and the internet most likely allowed for greater candor by research participants.

Future directions should include addressing the issue of the role of sexual attraction in body image research, the use of additional measures of body dissatisfaction with measures of BDD to better detect the role of appearance dissatisfaction, or subclinical levels of BDD with body depilation. Another possibility would be to revise the ATBHM scale and collecting more data to shore-up the factor structure. Revising the ATBHM scale might bolster the current factor structure, and then a confirmatory factor analysis of the scale would be appropriate. It might be important to investigate adding items to the scale that evaluate body hair by body sites other than just the back. Another fruitful direction may be distinguishing whether women have differential attitudes toward total body hair removal as compared with men's clipping to leave stubble. These questions, and others, were not addressed in the current version of the ATBHM (Boroughs, 2008) scale that was developed.

With the success of the findings related to social comparison theory, additional assessment using extant measures could help to better explain the phenomenology of body depilation and its genesis in men. Revisions of the BoDeQ measure would also be 
helpful to remove redundancies and develop the instrument to be more directed towards specifics based on body site rather than assuming body depilation techniques are uniform across all body sites.

The implications of these studies include a greater understanding of body depilation and its associated correlates including the role of appearance satisfaction, body areas sastisfaction, the drive for muscularity, gender role conflict, sexual orientation differences, race/ethnic differences, the role of the amount of extant body hair, and women's preferences. 


\section{References}

Across, A. (1989). Otoko no taimo to sengo nihonjin. (Men's body hair and the postwar Japanese). August 8: 47-61.

Agliata, D., \& Tantleff-Dunn, S. (2004). The impact of media exposure on males' body image. Journal of Social and Clinical Psychology, 23, 7-22.

American Psychiatric Association. (1994). Diagnostic and statistical manual of mental disorders (4th ed.). Washington, DC: Author.

American Psychiatric Association. (2000). Diagnostic and statistical manual of mental disorders (4th ed., Text rev.). Washington, DC: Author.

Basow, S. (1991). The hairless ideal: Women and their body hair. Psychology of Women Quarterly, 15, 83-96.

Basow, S., \& Braman, A. (1998). Women and body hair: Social perceptions and attitudes. Psychology of Women Quarterly, 22, 637-645.

Begier, E., Frenette, K., Barrett, N., Mshar, P., Petit, S., Boxrud, D., Watkins-Colwell, K., Wheeler, S., Cebelinski, E., Glennen, A., Nguyen, D., \& Hadler, J. (2004). A high-morbidity outbreak of Methicillin-Resistant Staphylococcus aureus among players on a college football team, facilitated by cosmetic body shaving and turf burns. Clinical Infectious Diseases, 39, 1446-1453.

Boroughs, M., \& Thompson, J. (2002). Body depilation in males: A new body image concern. International Journal of Men's Health, 1, 247-257. 
Boroughs, M., Cafri, G., \& Thompson, J. (2005). Male body depilation: Prevalence and associated features of body hair removal. Sex Roles, 52, 637-644.

Brown, T., Cash, T., \& Mikula, P. (1990). Attitudinal body-image assessment: Factor analysis of the body-self relations questionnaire. Journal of Personality Assessment, 55, 135-144.

Cafri, G., \& Thompson, J. (2004). Measuring male body image: A review of the current methodology. Psychology of Men and Masculinity, 5, 18-29.

Collins, D., Metzler, D., \& Williams, M. (Executive Producers). (2003). Queer Eye for the Straight Guy. Burbank, CA: Bravo.

Dikötter, F. (1998). Hairy barbarians, furry primates and wild men: Medical science and cultural representations of hair in China. In A. Hiltebeitel \& B.D. Miller (Eds.). Hair: Its Power and Meaning in Asian Cultures, New York: SUNY Press.

Dittmar, H. (2005). Vulnerability factors and processes linking sociocultural pressures and body dissatisfaction. Journal of Social and Clinical Psychology, 24, 10811087.

Dixson, B., Dixson, A., Baoguo, L., \& Anderson, M. (2007). Studies of human physique and sexual attractiveness: Sexual preferences of men and women in China. American Journal of Human Biology, 19, 88-95.

Dixson, B., Dixson, A., Morgan, B., \& Anderson, M. (2007). Human physique and sexual attractiveness: Sexual preferences of men and women in Bakossiland, Cameroon. Archives of Sexual Behavior, 36, 369-375. 
Dixson, A., Halliwell, G., East, R., Wignarajah, P., \& Anderson, M. (2003). Masculine somatotype and hirsuteness as determinants of sexual attractiveness to women. Archives of Sexual Behavior, 32, 29-39.

Festinger, L. (1954). A theory of social comparison processes. Human Relations, 7, 11740.

Fiske, S. (2004). Social Beings: A Core Motives Approach to Social Psychology. Hoboken, NJ: John Wiley \& Sons, Inc.

Franzoi, S. \& Klaiber, J. (2007). Body use and reference group impact: With whom do we compare our bodies? Sex Roles, 56, 205-214.

Frederick, D., Fessler, D., \& Haselton, M. (2005). Do representations of male muscularity differ in men's and women's magazines? Body Image, 2, 81-86.

Gettelman, T. E., \& Thompson, J. K. (1993). Actual differences and stereotypical perceptions in body image and eating disturbance: A comparison of male and female heterosexual and homosexual samples. Sex Roles, 29, $545-562$.

Gomes, L. (2001, September 5). That thicket of hair just spoils the view of all those muscles: Many young men are taking it off to look like guys in the pages of Men's Health. Wall Street Journal, p. A1.

Halliwell, E., Dittmar, H., \& Orsborn, A. (2007). The effects of exposure to muscular male models among men: Exploring the moderating role of gym use and exercise motivation. Body Image, 4, 278-287.

Heatheron, T.F., \& Polivy, J. (1991). Development and validation of a scale of measuring state self-esteem. Journal of Personality and Social Psychology, 60, 895-910. 
Heinberg, L., \& Thompson, J.K. (1992). Social comparison: Gender, target importance ratings, and relation to body image disturbance. Journal of Social Behavior and Personality, 7, 335-344.

Hobza, C., Walker, K., Yakushko, O., \& Peugh, J. (2007). What about men? Social comparison and the effects of media images on body and self-esteem. Journal of Men \& Masculinity, 8, 161-172.

Hope, C. (1982). Caucasian female body hair and American culture. The Journal of American Culture, 5, 93-99.

Hospers. H., \& Jansen, A. (2005). Why homosexuality is a risk factor for eating disorders in males. Journal of Social and Clinical Psychology, 24, 1188-1201.

Lewis, J. (1987). Caucasian body hair management: A key to gender and species identification in U.S. culture? Journal of American Culture, 10, 7-14.

Luciano, L. (2001). Looking good: Male body image in modern America. New York: Hill and Wang.

Lynch, S., \& Zellner, D. (1999). Figure preferences in two generations of men: The use of figure drawings illustrating differences in muscle mass. Sex Roles, 40, 833843.

Martins, Y., Tiggemann, M., \& Churchett, L. (2008). Hair today, gone tomorrow: A comparison of body hair removal practices in gay and heterosexual men. Body Image, 5, 312-316.

Martins, Y. \& Tiggemann, M (in press). The shape of things to come: Gay men's satisfaction with specific body parts. Psychology of Men and Masculinity. 
McCreary, D.R., Hildebrandt, T., Heinberg, L.J., Boroughs, M. S., \& Thompson, J.K. (2007). A review of body image influences on men's fitness goals and supplement use. American Journal of Men's Health, 1, 307-316.

McCreary, D.R., \& Sasse, D.K. (2000). An exploration of the drive for muscularity in adolescent boys and girls. Journal of American College Health, 48, 297-304.

Miller, E., \& Halberstadt, J. (2005). Media consumption, body image, and thin ideals in New Zealand men and women. New Zealand Journal of Psychology, 34, 189-195.

Miller, L. (2003). Male beauty work in Japan. In J.E. Roberson \& N. Suzuki (Eds.). Men and Masculinities in Contemporary Japan: Dislocating the Salaryman Doxa. London: Routledge.

Miller, L., Perdreau-Remington, F., Bayer, A., Diep, B., Tan, N., Bharadwa, K., Tsui, J., Perlroth, J., Shay, A., Tagudar, G., Ibebuogu, U., Spellberg, B. (2007). Clinical and epidemiologic characteristics cannot distinguish community-associated methicillin-resistant Staphylococcus aureus infection from methicillin-susceptible S. aureus infection: A prospective investigation. Clinical Infectious Diseases, 44, 471-482.

Morrison, T., Kalin, R., Morrison, M. (2004). Body-image evaluation and body-image investment among adolescents: A test of sociocultural and social comparison theories. Adolescence, 39, 571-592.

Olivardia, R., Pope, H., Borowiecki, J., \& Cohane, G. (2004). Biceps and body image: The relationship between muscularity and self-esteem, depression, and eating disorder symptoms. Psychology of Men and Masculinity, 5, 112-120. 
Pope, H., Gruber, A., Choi, P., Olivardia, R., \& Phillips, K. (1997). Muscle dysmorphia: An underrecognized form of body dysmorphic disorder. Psychosomatics, 38, $548-557$.

Pope, H., Phillips, K., \& Olivardia, R. (2000). The Adonis complex:The secret crisis of male body obsession. New York: Free Press.

Pope, H. Gruber, A., Mangweth, B., Bureau, B., deCol, C., \& Jouvent, R. et al. (2000). Body image perception among men in three countries. American Journal of Psychiatry, 157, 1297-1301.

Porche, D. (2007). Male body depilation. The Journal for Nurse Practitioners, 3, 14-15.

Rosen, J. (1996). Body dysmorphic disorder: Assessment and treatment. In J. K. Thompson (Ed.), Body image, eating disorders, and obesity: An integrative guide to assessment and treatment (pp. 149-170). Washington, DC: American Psychological Association.

Rosen, J. \& Reiter, J. (1996). Development of the body dysmorphic disorder examination. Behaviour Research \& Therapy, 34, 755-766.

Rosen, J., Reiter, J., \& Orosan, P. (1995). Cognitive-Behavioral body image therapy for body dysmorphic disorder. Journal of Consulting and Clinical Psychology, 63, 263-269.

Rosenberg, M. (1965). Society and the adolescent self-image. Princeton, NJ: Princeton University Press.

Schuler, L. (2000, May). How to lose your hair: A man's guide to waxing, shaving, plucking, burning, and shocking away unwanted body foliage. Men's Health, p. 4. 
Sheldon, W., Dupertuis, C., \& McDermott, E. (1954). Atlas of Men. New York: Harpers. Simpson, M. (1994, November 15). Here come the mirror men; Metrosexual men wear Paul Smith, use moisturizer, and know that vanity begins at home. The Independent, p. 22.

Simpson, M. (2002, July 22). Meet the metrosexual: He's well dressed, narcissistic and bun-obsessed. But don't call him gay. Salon, Retrieved January 4, 2005, from: http://archive.salon.com/ent/feature/2002/07/22/metrosexual/

Smith, H. (2000, July 10). Why Zorba can't keep his hair on. New Statesman, p. 12.

Stein, J. (1999, September 20). Shaving the body, Fantastic. Time,p. 12.

Stuever, H. (2000, August 3). Mr. Rug; for men, a hairy back is a closely held secret. Washington Post, p. C1.

Tabachnick, B. \& Fidell, L. (1996). Using Multivariate Statistics. New York, NY: Harper Collins.

Thompson, J.K. (1990). Body Image Disturbance: Assessment and Treatment. New York, NY: Elsevier

Thompson, J. \& Cafri, G. (2007). The Muscular Ideal: Psychological, Social, and Medical Perspectives. Washington, DC: American Psychological Association.

Thompson, J., Heinberg, L, \& Tantleff, S. (1991). The physical appearance comparison scale (PACS). The Behavioral Therapist, 14, 174-188.

Tiggemann, M., Martins, Y., \& Churchett, L. (2008). Beyond muscles: Unexplored parts of men's body image. Journal of Health Psychology, 13, 1163-1172.

Tiggemann, M., \& Kenyon, S. (1998). The hairless norm: The removal of body hair in women. Sex Roles, 39, 873-878. 
Toerien, M., \& Wilkinson, S. (2003). Gender and body hair: Constructing the feminine woman. Women's Studies International Forum, 26, 333-344.

Toerien, M., \& Wilkinson, S. (2004). Exploring the depilation norm: A qualitative questionnaire study of women's body hair removal. Qualitative Research in Psychology, 1, 69-92.

Trager, J. (2006). Pubic hair removal: Pearls and pitfalls. Journal of Pediatric and Adolescent Gynecology, 19. 117-123.

Tylka, T.L., Bergeron, D., \& Schwartz, J.P. (2005). Development and psychometric evaluation of the Male Body Attitudes Scale (MBAS). Body Image, 2, 161-175.

Ullerstam, L. (1966). The Erotic Minorities: A Swedish View. New York, NY: Grove Press.

van den Berg, P., Paxton, S., Keery, H., Wall, M., Guo, J., \& Neumark-Sztainer, D. (2007). Body dissatisfaction and body comparison with media images in males and females. Body Image, 4, 257-268. 
Appendices

\section{Demographic Questionnaire}

1) Please enter your date of birth: Month (e.g. for November enter ' 11 ')

Date

Year

2) Please enter your age:

3) Please check one of the following to describe your race/ethnicity (check one):

African American

Asian/Pacific Islander

Hispanic/Latino

Native American

Euro American

4) Did you grow up in the United States? __ Yes __ No

5) Please check on the highest level of education that you have achieved:

_ High School Diploma

College Freshman

College Sophomore

College Junior

College Senior

Master's Degree

Doctoral Degree (Ph.D., M.D., etc.)

Other (please specify)

6) Please check which best describes your present marital status:

Married

_ Single

Divorced

Remarried

7) Please enter your height in feet and inches: feet inches

8) Please enter your weight in pounds: 
9) Please estimate the number of times you weigh yourself per week:

10) Please enter an estimate of how much of each of the following types of exercise you engage in per week (in minutes) both inside and outside a gym (for example - for none enter ' 0 ', for 1 hour enter ' 60 ', etc.):

Aerobic Exercise, e.g. running, cycling, stair climbing elliptical (in a gym)

Aerobic Exercise (outside a gym)

Anaerobic Exercise, e.g. weightlifting, body building, strength training (in a gym)

Anaerobic Exercise (outside a gym)

11) Please check one of the following numbers that best describes your sexual attraction to others:

1-attracted to only the opposite sex

2-mostly attracted to the opposite sex but sometimes to the same sex

3 -attracted to both males and females equally

4-mostly attracted to the same sex but sometime to the opposite sex

5-attracted only to the same sex

12) Please check one of the following numbers that best describes your sexual behavior with others:

5-attracted only to the same sex

4-mostly attracted to the same sex but sometime to the opposite sex

3 -attracted to both males and females equally

2-mostly attracted to the opposite sex but sometimes to the same sex

1-attracted to only the opposite sex

13) Please check one of the following numbers that best describes your sexual fantasy toward others:

1-attracted to only the opposite sex

2-mostly attracted to the opposite sex but sometimes to the same sex

3 -attracted to both males and females equally

4-mostly attracted to the same sex but sometime to the opposite sex

5 -attracted only to the same sex 
14) Please check one of the following numbers that best describes your sexual orientation: 3- Heterosexual 2- Bisexual 1-Gay/Lesbian

15) Please enter an estimate of the total number of minutes per week that you view pornography (for example - for none enter " 0 ", for one hour enter " 60 ", for three hours enter "180", for five hours enter "300", etc.): 
Attitudes Toward Body Hair on Men (ATBHM; Boroughs, 2008).

(Instructions: Females) Below are a series of statements concerning body hair on men. Please read each item carefully and check your level of agreement for each statement using the following scale:

(Instructions: Sexual Minority Males) Below are a series of statements concerning body hair on men. When answering these questions, refer to men that you are attracted to. Please read each item carefully and check your level of agreement for each statement using the following scale:

$1=$ Strongly Disagree

$2=$ Disagree

$3=$ Neutral, neither agree nor disagree

$4=$ Agree

$5=$ Strongly Agree

1. Body hair on men is attractive.

2. Lack of body hair makes men look like women. (R)

3. Men should remove back hair.

4. Body hair on men is disgusting.

5. Body hair on men feels physically uncomfortable.

6. Men who remove or reduce their body hair should receive social disapproval.

7. Men's bodies are okay unshaved.

8. Body hair is masculine.

9. Men need to remove or reduce body hair in order to appeal to others. (R)

10. Body Hair removal or reduction makes men's skin feel stubbly.

11. Body hair makes men look like animals.

12. Removing or reducing body hair signals that a man is a "metrosexual".

13. Removing or reducing body hair signals that a man is gay.

14. Body hair on men is ugly.

15. Body hair makes men look mature.

16. Men should reduce or remove their body hair to look more muscular.

17. Back hair on men is disgusting.

18. Men who remove or reduce their body hair look cleaner.

19. Hairy men should remain hairy, and naturally smooth men should remain smooth.

20. Body hair on men feels good. (R)

21. Chest hair on men is masculine.

22. Men look more muscular without body hair.

23. Men appear more defined (cut) without body hair.

24. Men look cleaner without body hair.

$(\mathrm{R})=$ reverse scored item 


\section{Body Depilation Questionnaire (BoDeQ; Boroughs, Thompson \& Cafri, 2001; Revised Boroughs, 2008).}

For the next set of questions, we would like to ask about your body hair growth for specific body sites.

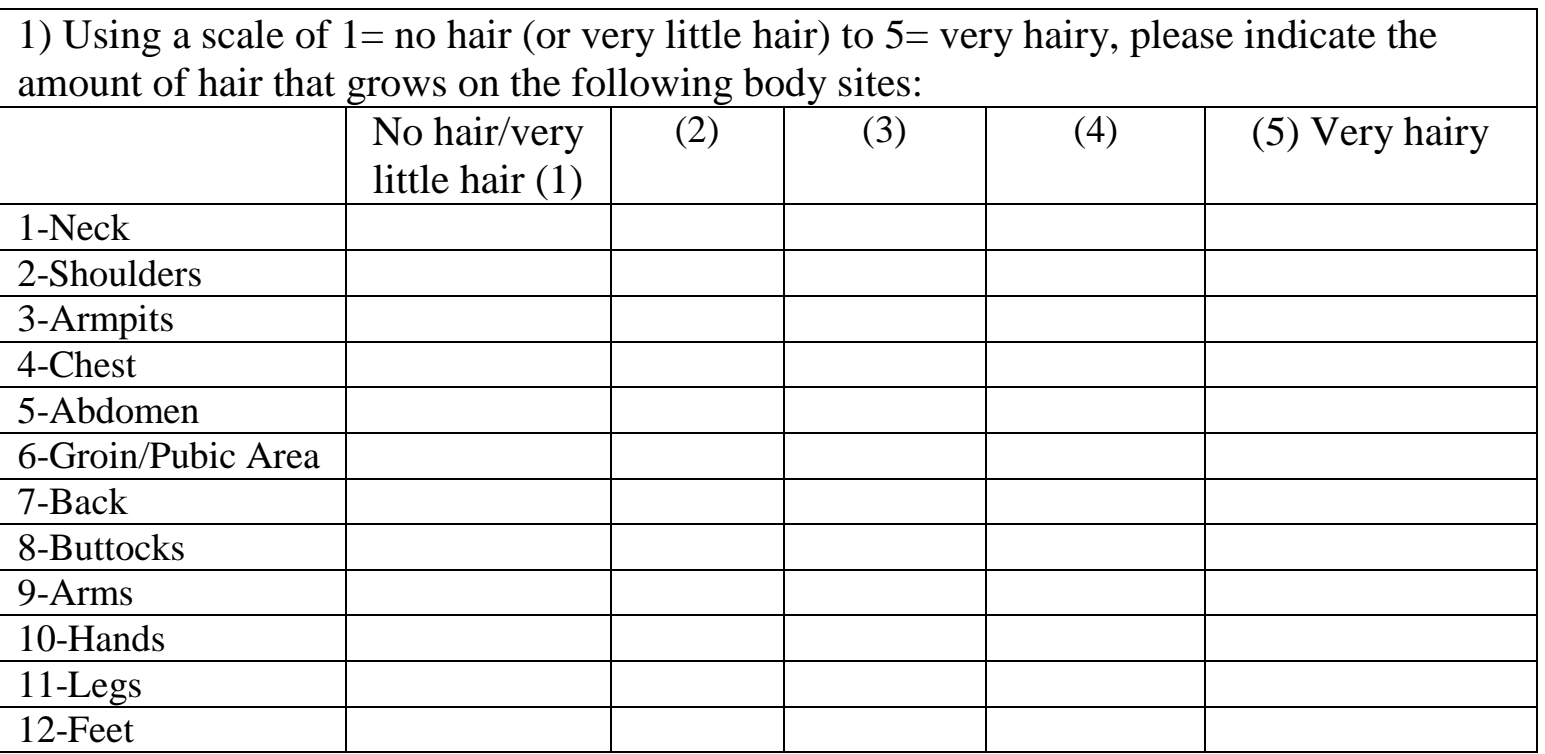

2) Do you or have you ever removed (e.g. shaved, waxed, etc.) or reduced (e.g. trimmed via electric razor, clippers etc.) any of your body hair from the neck down? (for example: chest, back, pubic area, underarms, legs, etc.) Yes No

[Participants that answer affirmatively to Question 2 proceed to the items below. Participants that answer 'no' to Question 2 advance to the next measure in the study.]

3) How many years have you been removing or reducing your body hair? (If less than one year, enter " 1 ")

4) How did others influence you to begin this behavior? (Check all that apply).
$\square$ overheard someone talking about it
$\square$ observed someone I know doing it
$\square$ talked to someone about it
$\square$ magazines and other media influenced me
$\square$ observed others that did it
$\square$ not influenced by others
Other (please specify) 
5) Does removing or reducing your body hair become less important during certain times of the year? (Check all that apply).
$\square$ yes, in the off-season for sports
$\square$ yes, when it is colder (climatic season)
$\square$ yes, when I am not in a relationship
$\square$ haven't been shaving or trimming long enough to know
$\square$ no, it does not become less important
Other (please specify)

6) Have any of the following injuries occurred as a result of your body depilation?

(Check all that apply).
$\square$ nicks
$\square$ cuts
$\square$ ingrown hair
$\square$ razor burn
$\square$ no injuries have ever occurred
$\square$ other injury

7) Why do you depilate your body hair? (Check all that apply).
$\square$ definition/muscularity
$\square$ cleanliness
$\square$ to avoid teasing
$\square$ sex appeal
$\square$ better healing
$\square$ youthfulness
$\square$ better sexual experience
$\square$ makes a part of my body appear larger
Other (please specify)

8) How do you remove or reduce your body hair? (Check all that apply).
$\square$ shaving cream
$\square$ electrolysis
$\square$ waxing at home
$\square$ chemical depilatories (e.g. Nair ${ }^{\text {TM }}$ or Neat ${ }^{\text {TM}}$ )
$\square$ regular razor
$\square$ laser hair removal
$\square$ scissors
$\square$ electric razor
$\square$ electric clippers
$\square$ waxing in a salon
$\square$ Nads TM
$\square$ creams
Other (please specify)

9) Please estimate the number of times per week you remove or reduce your body hair: 
10) Do you allow any visible re-growth before you resume the depilation process? No __ Yes

11) For the next three questions, please indicate the level of importance for removing or reducing your body hair using the following scale:

$1=$ extremely important

$2=$ moderately important

$3=$ somewhat important

$4=$ slightly important

$5=$ not important

a) Rate how important it is for you to remove or reduce your body hair when being seen by significant others.

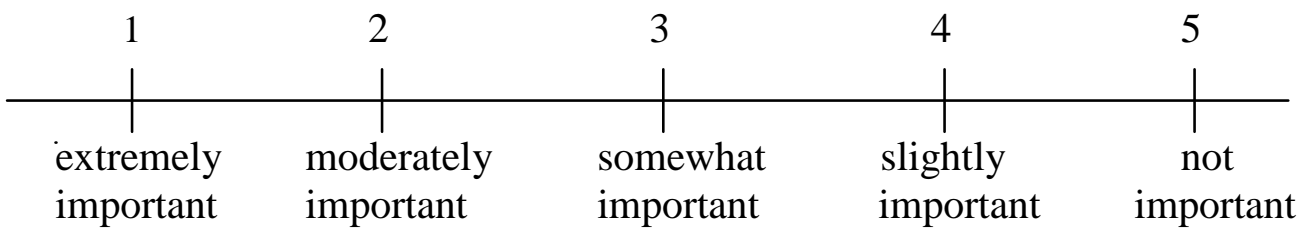

b) Rate how important it is for you to remove or reduce your body hair when being seen by friends.

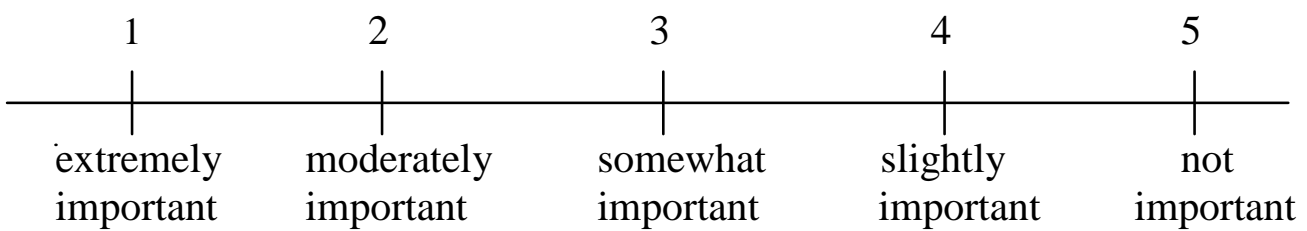

c) Rate how important it is for you to remove or reduce your body hair when being seen (by strangers) out in public.

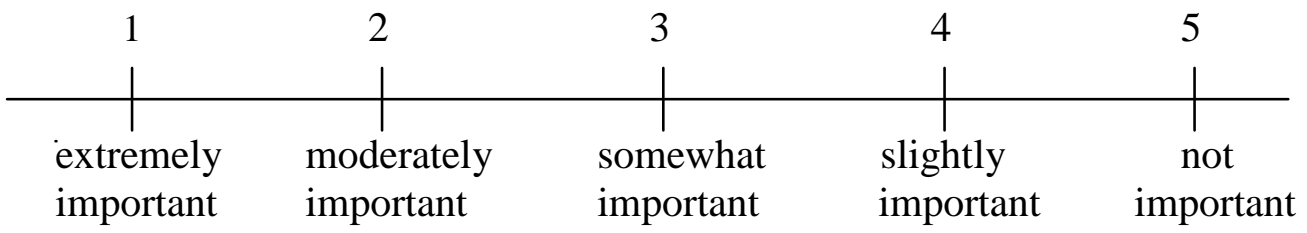

12) Have others mentioned to you that they notice that you have depilated your body hair? Yes No 
13) If you responded 'yes' to the previous question, please answer this item, if you responded 'no', then skip to the next item (\#14).

Rate the kind of feedback you have received from others related to your body hair depilation.

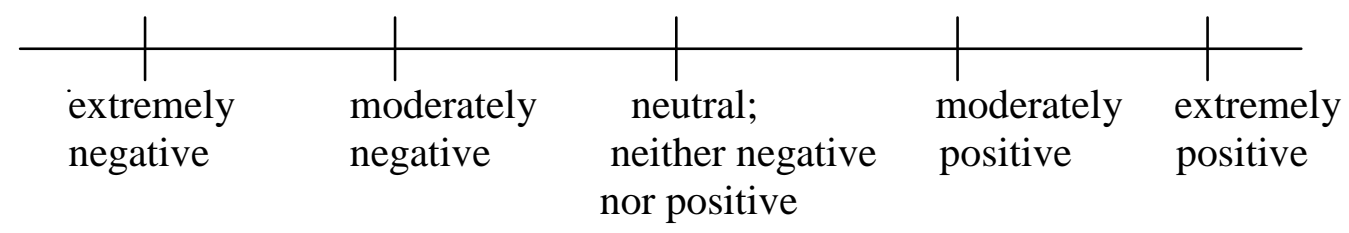

14) Do you feel differently about yourself or your body after you have "removed" or reduced your body hair compared to when it has grown back? Yes No

15) Please answer the next two questions with ratings from "extremely good" to "extremely bad".

a) Rate how you feel when you do not remove or reduce your body hair.

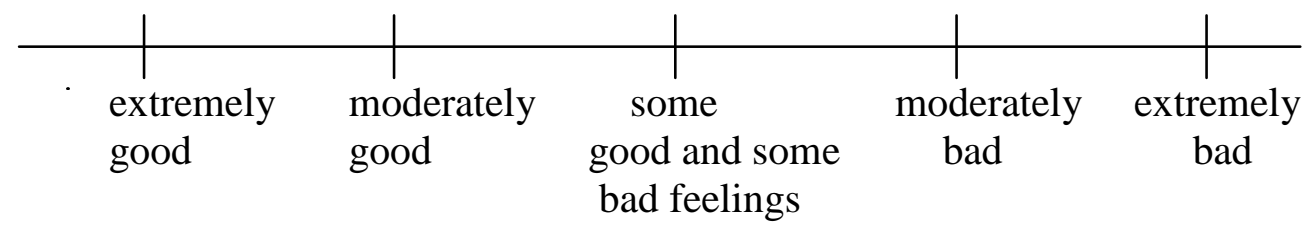

b) Rate how you feel if you have gone a few days without removing or reducing your body hair.

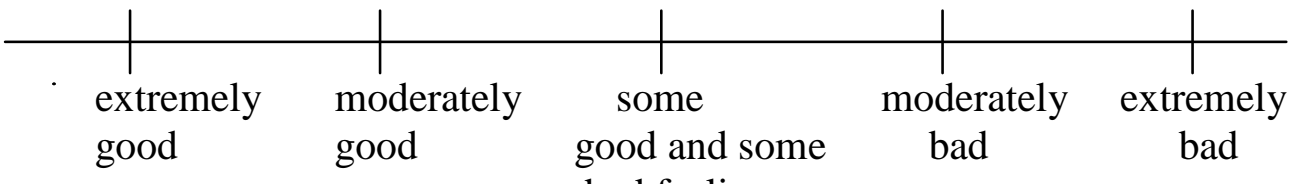

16) Rate how anxious you would be if you could not remove or reduce your body hair for a few weeks.

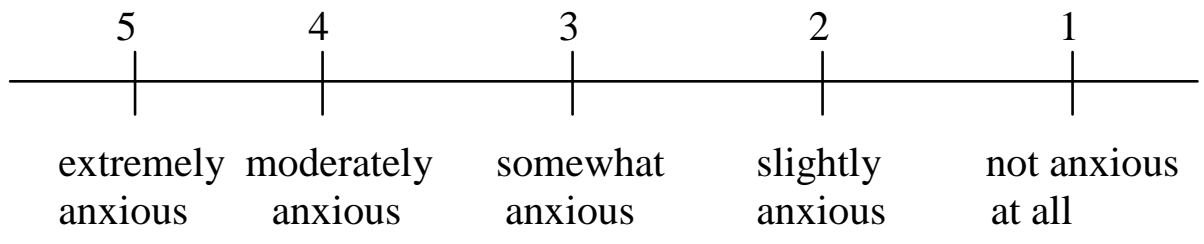


17) Using the following drop-down menus, please indicate the most frequently used METHOD of body hair removal or reduction that you use for each of the following body sites, and the FREQUENCY you depilate the hair at that site.

\begin{tabular}{|l|l|l|}
\hline Body Site List & \multicolumn{1}{|c|}{ Method(s) } & \multicolumn{1}{|c|}{ Frequency } \\
\hline 1-Neck & Regular razor & More than once daily \\
2-Shoulders & Electric razor & Daily \\
3-Armpits & Electric clippers & Twice weekly \\
4-Chest & Waxing at home & Weekly \\
5-Abdomen & Nads & Twice monthly \\
6-Groin/Pubic Area & Depilatory creams (e.g. Nair ${ }^{\mathrm{TM}}$ or Veet $^{\mathrm{TM}}$ ) & Monthly \\
7-Back & Chemical Depilatories & Less than once monthly \\
8-Buttocks & Scissors & \\
9-Arms & Electrolysis & \\
10-Hands & Laser Hair Removal & \\
11-Legs & No Hair at this site & \\
12-Feet & This site not depilated & \\
& other & \\
\hline
\end{tabular}

18) Please refer to your observations of body depilation by others to answer the next four items.

a) How often do you see (notice) other men at the gym that shave or trim their body hair?

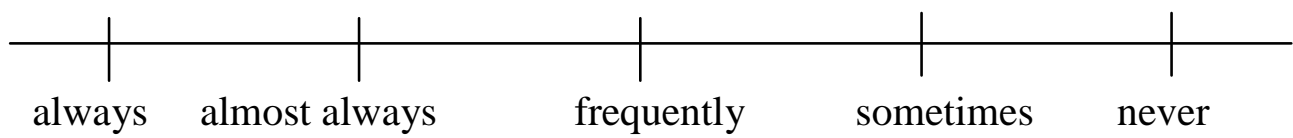

b) How often do you see (notice) other male friends that shave or trim their body hair?

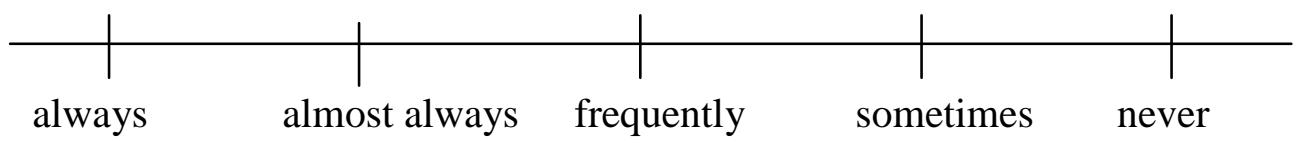

c) How often do you see (notice) other male classmates that shave or trim their body hair?

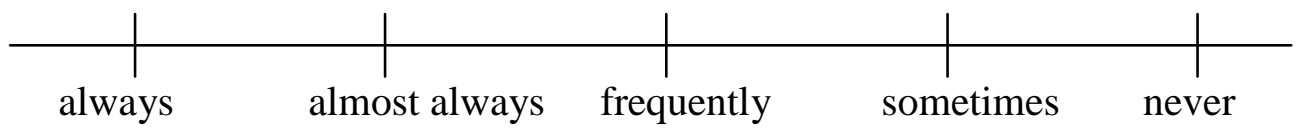

d) How often do you see (notice) others men anywhere else that shave or trim their body hair?

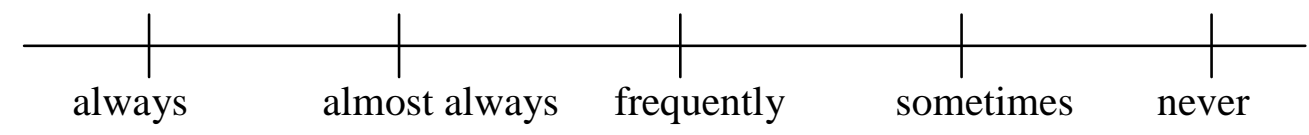




\section{Physical Appearance Comparison Scale (PACS; Thompson, Heinberg, \& Tantleff, 1991; Revised Boroughs, 2008)}

Use the following scale ranging from 'never' to 'always' to answer the next 5 items by checking the answer that comes closest to how you feel:

\begin{tabular}{|c|l|l|l|l|l|l|}
\hline & & Never & Seldom & Sometimes & Often & Always \\
\hline 1. & $\begin{array}{l}\text { At parties or other social events, I } \\
\text { compare my physical appearance to } \\
\text { the physical appearance of others. }\end{array}$ & & & & & \\
\hline 2. & $\begin{array}{l}\text { The best way for a person to know if } \\
\text { they are overweight or underweight is } \\
\text { to compare their body shape to the } \\
\text { body shape of others. }\end{array}$ & & & & & \\
\hline 3. & $\begin{array}{l}\text { At parties or other social events, I } \\
\text { compare how I am dressed to how } \\
\text { other people are dressed. }\end{array}$ & & & & & \\
\hline 4. & $\begin{array}{l}\text { Comparing your "looks" to the } \\
\text { "looks" of others is a bad way to } \\
\text { determine if you are attractive or } \\
\text { unattractive. }\end{array}$ & & & & & \\
\hline 5. & $\begin{array}{l}\text { In social situations, I sometimes } \\
\text { compare my body shape to the body } \\
\text { shape of other people. }\end{array}$ & & & & & \\
\hline
\end{tabular}




\section{Multidimensional Body Self-Relations Questionnaire - Body Areas Satisfaction Scale (MBSRQ-BASS; Brown, Cash \& Mikula, 1990; Revised Boroughs, 2008)}

Instructions:

Using the following scale for the next 10 items, indicate how dissatisfied or satisfied you are with each of the following areas or aspects of your body:

\begin{tabular}{|l|l|l|l|l|l|l|}
\hline & & $\begin{array}{l}\text { Very } \\
\text { dissatisfied }\end{array}$ & $\begin{array}{l}\text { Mostly } \\
\text { dissatisfied }\end{array}$ & $\begin{array}{l}\text { Neither } \\
\text { satisfied nor } \\
\text { dissatisfied }\end{array}$ & $\begin{array}{l}\text { Mostly } \\
\text { satisfied }\end{array}$ & $\begin{array}{l}\text { Very } \\
\text { satisfied }\end{array}$ \\
\hline 1. & $\begin{array}{l}\text { Face (facial features, } \\
\text { complexion) }\end{array}$ & & & & \\
\hline 2. & $\begin{array}{l}\text { Hair (on head-color, } \\
\text { thickness, texture) }\end{array}$ & & & & & \\
\hline 3. & $\begin{array}{l}\text { Lower torso (buttocks, hips, } \\
\text { thighs, legs) }\end{array}$ & & & & & \\
\hline 4. & Mid torso (waist, stomach) & & & & & \\
\hline 5. & $\begin{array}{l}\text { Upper torso (chest, shoulders, } \\
\text { arms) }\end{array}$ & & & & & \\
\hline 6. & Muscle tone & & & & & \\
\hline 7. & Weight & & & & & \\
\hline 8. & Height & & & & & \\
\hline 9. & Overall appearance & & & & & \\
\hline 10. & $\begin{array}{l}\text { Body hair (amount, locations, } \\
\text { coarseness) }\end{array}$ & & & & & \\
\hline
\end{tabular}

